\title{
Can a Financial Transaction Tax Prevent Stock Price Booms?
}

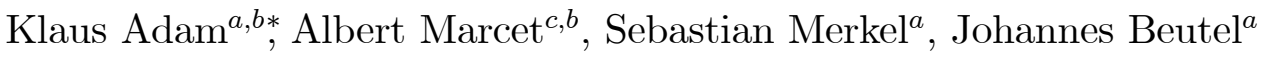 \\ ${ }^{a}$ University of Mannheim; ${ }^{b}$ CEPR; \\ ${ }^{c}$ Institut d'Anàlisi Econòmica (CSIC), ICREA, UAB, MOVE, Barcelona GSE
}

July 10, 2015

\begin{abstract}
We present a stock market model that quantitatively replicates the joint behavior of stock prices, trading volume and investor expectations. Stock prices in the model occasionally display belief-driven boom and bust cycles that delink asset prices from fundamentals and redistribute considerable amounts of wealth from less to more experienced investors. Although gains from trade arise only from subjective belief differences, introducing financial transactions taxes (FTTs) remains undesirable. While FTTs reduce the size and length of boom-bust cycles, they increase the likelihood of such cycles, therby overall return volatility and wealth redistribution. Contingent FTTs, which are levied only above a certain price threshold, give rise to problems of equilibrium multiplicity and non-existence.
\end{abstract}

Keywords: financial transactions tax, Tobin tax, asset price booms

JEL classification: G12, D84

\section{Introduction}

Following the financial crisis, there has been a widespread desire among policymakers to introduce financial transaction taxes (FTTs). The European Commission, for example, proposed the introduction of FTTs in September 2011. Subsequently, France introduced in 2012 a $0.1 \%$ tax on stock market and related transactions and has recently increased the tax rate to $0.2 \%$. Italy introduced a $0.1 \%$ tax on stock market transactions in $2013 .{ }^{1}$

${ }^{*}$ Corresponding author: Klaus Adam, Department of Economics, University of Mannheim, L7,3-5, 68131 Mannheim, Germany, adam@uni-mannheim.de. We thank Eduardo Dávila, Martin Ellison, Guido Lorenzoni, Carsten Trenkler, Mirko Wiederholt, seminar participants at the 2014 JME Gerzensee Conference, Deutsche Bundesbank, European Central Bank, the 2015 CSEF-CIM-UCL Conference in Ischia, the 2015 Barcelona Summer Forum on Finance and Macroeconomics, the 2015 Conference on Expectations in Dynamic Macroeconomic Model in Eugene, Oregon for helpful comments and suggestions. Klaus Adam acknowledges funding from ERC starting grant no. 284262, Boom \& Bust Cycles. Albert Marcet acknowledges support from Programa de Excelencia del Banco de España, Plan Nacional (Ministry of Education), SGR (Generalitat de Catalunya) and ERC advanced grant no. 324048. All errors remain ours.

${ }^{1}$ FTTs are already a widely used tax instrument in housing markets. Spain, for example, levies an $8 \%$ transaction tax on real estate transactions and Germany levies a $5 \%$ tax, both additionally levy capital gains 
One of the stated policy objectives of the European Commission is that FTTs should 'discourage financial transactions which do not contribute to the efficiency of financial markets'. The present paper seeks to analyze to what extent FTTs actually increase the efficiency of stock market transactions and stock market prices. In particular, it investigates whether FTTs can prevent boom and bust like dynamics in stock prices; over recent decades such price dynamics have become pervasive in a number of important stock markets and have contributed to the redistribution of wealth between different kinds of investors. ${ }^{2}$ The effect that FTTs have on boom-bust like dynamics in stock markets should thus be of prime importance to policymakers.

To analyze this issue, we use a modeling framework that can generate stock price fluctuations roughly of the size observed in the data, including occasional large upswings and reversals in stock market prices. The model also quantitatively replicates important data moments characterizing the behavior of trading volume, as well as its comovement with stock prices and investor expectations. Credibly replicating the behavior of trading volume appears key for an analysis that seeks to understand the effects of taxing trading activity and is a distinguishing feature of the present analysis. ${ }^{3}$

Besides being quantitatively plausible, our modeling framework gives FTTs the best possible chance to generate positive welfare effects: first, we consider a framework where subjective belief components cause asset prices not to be fully efficient, so that there is at least in principle - room for increasing the efficiency of financial market prices; second, within the presented framework, the gains from trade exist only in subjective terms, i.e., due to belief differences, so that taxing trading activity may appear desirable on a priori grounds, see Simsek (2013); third, we abstract from a number of adverse consequences likely to be associated with the introduction of FTTs, such as costly evasive behavior, which may involve redirecting orders to other exchanges, the adverse liquidity effects resulting from financial market fragmentation, or the costly creation of alternative financial instruments that are not subject to the tax.

Our main finding is that even within this very conducive setting, the introduction of FTTs fails to 'discourage transactions which do not contribute to the efficiency of financial markets'. Indeed, we find that the introduction of FTTs increases the likelihood that the stock market embarks on a significant boom and bust cycle in valuation, and thereby increases the overall amount of wealth redistribution. The reasons for this finding are subtle, as we explain

taxes.

${ }^{2}$ See Brunnermeier and Nagel (2004) for evidence on how the tech stock boom and bust around the year 2000 redistributed wealth between hedge fund and other investors.

${ }^{3}$ See section 2 . for a discussion of the related literature. 
below, but show that FTTs may actually not be a suitable policy instrument for increasing the efficiency of stock markets.

The modeling framework used in the present paper builds upon prior work by Adam, Marcet and Beutel (2015), which replicates stock price behavior within a representative agent framework with time separable preferences. The present analysis adds (1) by introducing investor heterogeneity and thereby equilibrium trade, (2) by showing that the resulting trading patterns are empirically plausible, and (3) by studying the pricing and welfare effects of introducing FTTs.

While the equilibrium pricing patterns of the representative agent model in Adam, Marcet and Beutel (2015) prove rather robust to introducing agent heterogeneity, i.e., stock prices continue to be very volatile and to display occasional boom-bust cycles, the addition of agent heterogeneity helps in generating auto-correlated trading volume, trading volume that correlates positively with absolute price changes, and trading volume that correlates positively with investor disagreement, in line with what is found in the data.

The presented model is one where boom-bust dynamics arise from subjective price beliefs, but in a setting where investors take fully optimal investment decisions given their beliefs, following Adam and Marcet (2011). The introduction of subjective stock price beliefs is motivated by empirical evidence presented in Adam, Marcet and Beutel (2015), who show that the joint dynamics of realized capital gains and capital gain expectations, as observed from survey data, are strongly inconsistent with the rational expectations hypothesis. This implies - amongst other things - that rational asset price bubbles, e.g., those derived in classic work by Froot and Obstfeld (1991), are inconsistent with the joint dynamics of actual and expected capital gains in the data.

Following Adam, Marcet and Beutel (2015), we consider investors who hold subjective stock price beliefs of a kind such that Bayesian updating causes investors to extrapolate (to different degrees) past capital gains into the future. The degree of extrapolation is thereby calibrated to the one that we document to be present in survey data. In particular, we show that less experienced stock market investors extrapolate more compared to investors with longer investment experience.

Extrapolative behavior, which gives rise to investor optimism and pessimism, potentially supports a strong argument in favor of introducing FTTs. Specifically, in our setting, price booms emerge because investors become optimistic once they see past prices going up, causing them to bid up today's prices, thereby creating additional optimism in the next period and further price increases. FTTs can prevent investors from trading on their optimistic beliefs, i.e., prevent them from bidding up prices once optimism has increased, thereby 
preventing the positive feedback loop between price increases and increased optimism just described.

While intuitively plausible, this argument ignores an important additional consequence of FTTs. By preventing agents from trading, even arbitrarily small exogenous shocks to stock supply can have a disproportionately large effect on realized prices. Specifically, linear transaction taxes imply that investors, whose stockholdings are close to their subjectively optimal level, do not want to trade, unless there is a significant change in the stock price. ${ }^{4}$ As a result, FTTs can increase price volatility in normal times. With realized prices feeding into investors' beliefs, due to extrapolative behavior, this ultimately increases the likelihood that the stock market embarks on a large self-fueling boom and subsequent bust.

Our quantitative analysis shows that FTTs manage to decrease the size and duration of stock price booms, including the volatility of prices during boom times. At the same time, FTTs increase price volatility during normal times. ${ }^{5}$ The predicted effect of a $4 \%$ FTT is an increase by one third of the number of stock price boom episodes relative to the case without taxes. Since price and return volatility is higher during boom times, the overall effect of FTTs is to increase stock price volatility.

Motivated by the observation that it is undesirable to levy FTTs in normal times, as they increase price volatility and thereby the likelihood of boom-bust cycles, we also consider the effects of state contingent taxes that are only levied once prices exceed a certain threshold. We show that such taxes give rise to non-continuous stock demand functions and thereby to problems of equilibrium multiplicity and non-existence. State-contingent transaction taxes appear problematic on these grounds.

The remainder of this paper is organized as follows. Section 2. discusses some of the related literature. Section 3. provides basic facts about the joint behavior of stock prices, trading volume and investor expectations that we seek to quantitatively match within our asset pricing framework. Section 4. introduces the asset pricing model. Section 5. shows that the model performs poorly in terms of replicating price and trading dynamics when investors hold rational price expectations. Section 6. evaluates the quantitative performance of the model with subjective price beliefs and in the absence of a transactions tax. In section 7. we show how stock price boom and bust dynamics redistribute wealth between different

\footnotetext{
${ }^{4}$ This is so because the gains from trade are of second order close to the optimum, while the cost of the tax are of first order.

${ }^{5}$ Normal times are times that are not classified as boom times. Boom times begin when the quarterly price dividend ratio exceeds a certain level and end when the PD ratio falls below a certain lower level. In our numerical application, we set the first threshold to 250 and latter to 200. Results turn out to be are rather robust to the precise threshold values.
} 
investor types. Section 8. presents the implications of introducing linear FTTs and section 9. considers the effects of state-contingent taxes. A conclusion briefly summarizes. Technical material and information about the employed data sources is summarized in an appendix.

\section{Related Literature}

The present paper is closely connected to an extensive literature on financial transaction taxes going at least back to the well-known proposal by Tobin (1978). We provide here a selective overview of the literature, making reference to work that is most closely related to the present paper.

In a comprehensive theoretical study, Dávila (2013) determines optimal linear transaction taxes for a setting where investors hold heterogeneous beliefs. He shows that the optimal transaction tax of a social planner who maximizes social welfare under her own (possibly different) probability beliefs, depends on the cross-sectional covariance between investors' beliefs and equilibrium portfolio sensitivities.

Scheinkman and Xiong (2003) analyze how asset price bubbles and trading volume are affected by transactions taxes in a setting with risk neutral investors who face a short-sale constraint and who hold different beliefs because they assign different information content to publicly available signals. In their setting, transaction taxes strongly affect trading volume but may have only a limited effect on the size of asset price bubbles.

The present paper adds to these contributions by considering the effects of FTTs within a quantitatively credible setting that replicates important data moments describing the joint behavior of stock prices, trading volume and investor expectations. Furthermore, by incorporating learning from market prices, investors' belief distortions depend in important ways

on market outcomes. This gives rise to feedback effects that are absent in models in which agents consider market prices to offer only redundant information.

In related work, Buss et al. (2013) consider the effects of FTTs and other policy instruments on stock market volatility in a production economy in which some stock market participants overinterpret the information content of public signals, as in Dumas et al. (2009). The present paper considers an endowment economy but evaluates model performance also with regard to the ability to match trading activity. Similar to our findings, Buss et al. (2013) show how financial transaction taxes increase the volatility of stock market returns.

With financial transaction taxes being almost equivalent to trading costs, the present paper also relates to the transaction costs literature. As in Constantinides (1986), transaction costs generate within the present setup partially flat demand curves, see also subsequent work 
by Aiyagari and Gertler (1991) and Heaton and Lucas (1996). Different from Constantinides (1986), the asset price effects of transaction costs fail to be of second order within the present setting because we consider agents that use price realizations to update beliefs about the price process. Guasoni and Muhle-Karbe (2013) and Vayanos and Wang (2014) provide recent surveys of the transaction cost literature.

Empirical evidence on the volatility effects of financial transaction taxes is provided in Umlauf (1993), Jones and Seguin (1997) and Hau (2006). These studies tend to find that market volatility increases with the introducing of a tax, see also McCulloch and Pacillo (2011) for a recent overview of the empirical literature. Coelho (2014) and Colliard and Hoffmann (2015) analyze the recent experiences with the introduction of FTTs in France and Italy, documenting how FTTs increase price volatility and reduce market depth.

The market microstructure literature also studies financial transaction taxes, focusing on the differential impact that such taxes have on the participation of noise traders, which create exogenous market volatility or mispricing, versus the participation of informed traders who evaluate prices according to fundamentals, see for example Jeanne and Rose (2002) or Hau (1998). The general conclusion of this theoretical literature is that if financial transaction taxes cause noise traders to participate less in the market, then market volatility can fall as a result.

\section{Stock Prices, Price Expectations and Trading Volume: Empirical Evidence}

This section documents key facts about the joint behavior of U.S. stock prices, investors' price expectations and stock market trading volume that we seek to quantitatively replicate with our asset pricing model. The next section presents empirical evidence about stock price behavior, the behavior of dividends and the behavior of average stock price expectations. Section 3.2. complements this with key facts about the behavior of trading volume and its relation with price behavior and the behavior of price expectations. It shows - amongst other things - that trading volume correlates positively with disagreement across investors about future prices. Finally, section 3.3. shows that disagreement between investors can be systematically related to investors' stock market experience.

\subsection{Stock Prices, Dividends and Average Price Expectations}

Table 1 presents key facts about the behavior of quarterly U.S. stock prices, dividends and stock return expectations as available from survey data. ${ }^{6}$ The facts presented in table

\footnotetext{
${ }^{6}$ The data sources used in this and the subsequent sections are described in appendix A1..
} 
1 are the main data moments guiding the analysis in Adam, Marcet and Beutel (2015) and we summarize them here for convenience. ${ }^{7}$

Table 1 shows that the average quarterly price dividend ratio $(E[P D])$ is around 140 and has a standard deviation $(s t d(P D))$ of approximately half its average value. ${ }^{8}$ Stock prices are thus very volatile. The quarterly auto-correlation of the price dividend (PD) ratio $\left(\operatorname{corr}\left(P D_{t}, P D_{t-1}\right)\right)$ is 0.98 , showing that deviations of the $\mathrm{PD}$ ratio from its sample mean are very persistent over time. As a result, quarterly real stock returns are very volatile, with a standard deviation $\left(s t d\left(r^{s}\right)\right)$ of around $8 \%$ per quarter. Real stock returns are thus much more volatile than real dividend growth, which has a standard deviation $\left(\operatorname{std}\left(D_{t} / D_{t-1}\right)\right)$ of just $1.92 \%$. The mean real stock return $\left(E\left[r^{s}\right]\right)$ is $1.89 \%$ per quarter and much higher than the average growth rate of real dividends $\left(E\left[D_{t} / D_{t-1}-1\right]\right)$, which equals $0.48 \%$ per quarter.

Table 1 also documents that the average investor's expected real returns in the UBS survey correlates strongly and positively with the $\mathrm{PD}$ ratio $\left(\operatorname{corr}\left(P D_{t}, \bar{E}_{t} R_{t+1}\right)\right)$ : the correlation equals 0.79. ${ }^{9}$ Adam, Marcet and Beutel (2015) show that this fact is robust against using other survey data sources and against alternative ways to distill expectations from the survey data. They also show that this fact is inconsistent with investors holding rational price expectations, which is why we include the correlation between the PD ratio and expected returns in the set of data moments that we seek to match.

[Table 1 about here]

\subsection{Trading Volume, Stock Prices and Disagreement}

This section presents empirical facts about trading activity and its comovement with prices and price expectations. It shows that trading volume is highly persistent, that trading volume is largely uncorrelated with stock market valuation, instead correlates positively with absolute price changes. Furthermore, it documents - to our knowledge for the first time - that aggregate trading volume and disagreement about future aggregate stock market returns, as measured by survey data, are positively correlated.

\footnotetext{
${ }^{7}$ We include here all asset pricing facts considered in Adam, Marcet and Beutel (2015), except for those involving the bond market, as the present model does not feature a bond market.

${ }^{8}$ The quarterly PD ratio is defined as the price over quarterly dividend payments, see appendix A1. for further details.

${ }^{9}$ The number reported in table 1 uses the mean of the expected returns of the own portfolio return expectations of all investors in the UBS survey. The survey data are avaialable from 1998:Q2 to 2007:Q2 and have been transformed into real values using the median of expected inflation reported in the survey of professional forecasters.
} 
The finance literature studies a range of empirical measures to capture trading activity, see Lo and Wang (2009) for an overview. To account for trading in individual shares, Lo and Wang argue that 'shares traded divided by shares outstanding is a natural measure of trading activity when viewed in the context of standard portfolio theory and equilibrium asset-pricing models' (p.243). Clearly, for individual shares, this measure is identical to using the dollar volume of shares traded divided by the dollar volume of shares outstanding. Since this latter measure aggregates more naturally across different stocks and since we are interested in the aggregate stock market, we use the dollar volume of shares traded over the dollar volume of share outstanding as our preferred measure of trading volume.

We aggregate daily trading volume into a quarterly series by summing up the daily trading volumes over the quarter, following Lo and Wang (2009). While being standard, this procedure is likely going to lead to an overstatement of the model relevant trading volume, as many of the daily trades recorded in the data may be reversed with opposing trades within the same quarter. Indeed, with the advent of high frequency trading strategies, many of the recorded trades are likely to be undone within seconds, if not milliseconds. Dealing properly with this issue in the data is difficult, as it would require information about individual portfolios of all investors. We seek to account - at least partially - for the increasing share of high-frequency trades over time, therefore use detrended data on trading volume. Since detrending can affect the cyclical properties of the trading volume series, we report below only facts that turn out to be robust to a range of plausible detrending methods.

Figure 1 depicts the (undetrended) quarterly trading volume of the U.S. stock market, where data is available from January 1973. Trading volume displays a clear upward trend over time. In the early 1970's trade during a quarter amounted to around 5\% of the market value of outstanding shares; at the end of the sample period this number reaches close to $50 \%$; the data also shows temporary spikes in trading volume around the 1987, 2000 and 2008 stock market busts.

[Figure 1 about here]

Table 2 presents a number of facts about detrended trading volume. As a baseline, we use simple linear detrending, but the table also displays outcomes for other commonly used detrending methods. In particular, it considers linear-quadratic detrending, the outcomes obtained from HP-filtering with a smoothing parameter of 1600, as well as so-called moving average (MA) detrending, which normalizes trading volume by the average trading volume recorded in the preceding four quarters. 
Table 2 shows that trading volume displays considerable autocorrelation across quarters. The autocorrelation is statistically significant at the $1 \%$ level for all detrending methods. ${ }^{10}$ For higher frequencies, this is a well-known fact that has been documented in the finance literature, we show it here for the quarterly frequency at which we will evaluate our asset pricing model.

Table 2 also shows that there exists no statistically significant correlation between trading volume and the level of the PD ratio. This illustrates that claims about the existence of a high correlation between the level of stock prices and trading volume, see for example Scheinkman and Xiong (2003) and the references cited therein, disappear once one removes the trend displayed by trading volume. ${ }^{11}$

The previous finding does not imply that trading volume and prices are unrelated. Indeed, as table 2 documents, trading volume correlates positively and in a statistically highly significant way with absolute price changes. This finding holds again for all detrending methods. It is in line with patterns documented by Karpoff (1987) and shows that periods of high volume are associated with large price changes.

[Table 2 about here]

The facts presented in table 2 are fairly standard in the light of the existing finance literature studying trading volume. We complement these facts below with additional empirical evidence on the relationship between trading volume and belief disagreement. Models in which investors disagree about the future prospects from investment have a long tradition in the finance literature, see Hong and Stein (2007) for a survey. We document in table 3 below that there exists a fairly robust positive correlation between aggregate trading volume and the amount of cross-sectional disagreement about future aggregate stock market returns.

Table 3 reports the correlation between trading volume and the cross-sectional standard deviations of real survey return expectations $\left(\operatorname{corr}\left(T V_{t}, \operatorname{std}\left(\widetilde{E}_{t}^{i} R_{t+1}\right)\right)\right)$, as obtained from various survey data sources. ${ }^{12}$ The point estimate of the correlation is always positive and often statistically significant when using linear or linear-quadratic detrending or the HP filter. The evidence is less strong when detrending trading volume using the moving average

\footnotetext{
${ }^{10}$ We test the null hypothesis $H_{0}: \operatorname{corr}(\cdot, \cdot)=0$ in this and subsequent tables using robust standard errors, following Roy and Cléroux (1993), which are implemented with a Newey-West estimator with 4 leads and lags.

${ }^{11}$ Our findings also hold true if one uses data only up to the year 2006, which shows that results are not driven by the recent financial crisis.

${ }^{12}$ Since the Shiller survey asks for expected capital gains, the reported correlations for this survey pertain to the cross-sectional dispersion of capital gain expectations.
} 
approach, but is otherwise rather robust. Furthermore, to document that results are not driven by outliers in the surveys, table 3 also reports the correlation between detrended trading volume and the inter-quartile range (IQR) of the cross-section of survey expectations $\left(\operatorname{corr}\left(T V_{t}, I Q R\left(\widetilde{E}_{t}^{i} R_{t+1}\right)\right)\right){ }^{13}$ Results turn out to be robust towards using this alternative dispersion measure.

Overall, the evidence in table 3 shows that trading volume and disagreement are positively correlated in the data.

[Table 3 about here]

\subsection{Disagreement and Stock Market Experience}

Given the evidence presented in the previous section, which shows that investor disagreement is systematically related to trading volume, this section explores potential sources of investor disagreement more closely. In particular, it shows that disagreement can be partly related to investor experience: the price expectations of investors with less stock market experience are more heavily influenced by recent stock market performance than those with more experience.

Adam, Marcet and Beutel (2015) show that the empirical time series behavior of the average price growth expectation in the UBS survey data $\left(\bar{E}_{t}\left[P_{t+1} / P_{t}\right]\right)$ can be captured very well by an extrapolative updating equation of the form

$$
\bar{E}_{t}\left[P_{t+1} / P_{t}\right]=\bar{E}_{t-1}\left[P_{t} / P_{t-1}\right]+g\left(\frac{P_{t}}{P_{t-1}}-\bar{E}_{t-1}\left[P_{t} / P_{t-1}\right]\right),
$$

which stipulates that the average investor extrapolates observed capital gains into the future. We document below that investors with different numbers of years of experience extrapolate to different degrees.

Figure 2 depicts the evolution of quarterly real price growth expectations held by investors with different years of stock market experience, as available from the UBS survey. ${ }^{14,15}$ It

\footnotetext{
${ }^{13}$ For the CFO survey, we do not observe individual survey responses or the interquartile range, thus cannot perform this robustness check.

${ }^{14}$ We choose experience groups with equidistant group boundaries (except for the highest group) and in a way that groups are approximately of similar size. The reported results are robust to using different numbers of groups or different group boundaries, provided one does not consider too many groups, which causes results to become more noisy.

${ }^{15}$ The figure reports the 'own portfolio' return expectations from the UBS survey, as these are available for a
} 
shows that in the year 1999 and until the beginning of the year 2000, when prior stock market returns have been very high due to the preceding tech stock boom, it is the less experienced investors that tend to be most optimistic about future capital gains. Indeed, investors with 0-5 years of experience expect an average real capital gain of around 3.5\% per quarter, i.e., a real gain of about $14 \%$ per year, while the most experienced group expects considerably lower capital gains (albeit still very high ones by historical standards). Following the subsequent stock market bust, belief dispersion across investor groups significantly narrows and reaches a low point during the stock market trough in the year 2003. Clearly, this happens because less experienced investors updated expectations more strongly during the market bust. Following the stock market recovery after the year 2003, belief dispersion widened again, with the least experienced investor group then holding once more the highest return expectations, while the two most experienced groups hold the lowest expectations.

Figure 2 suggests, in line with evidence presented in Malmendier and Nagel (2011), that the capital gain expectations of less experienced investors react more strongly to realized capital gains. We formally check this hypothesis by estimating the updating parameter $g$ in equation (1) for each experience group separately, using the same approach as employed in Adam, Marcet and Beutel (2015). Table 4 reports the estimation outcome and shows that the updating parameter is monotonically decreasing with experience, with the updating parameter of the most inexperienced group of investors being approximately $75 \%$ higher than that of the most experienced investor group. The estimated updating gains are all statistically significantly different from zero at the $1 \%$ level. ${ }^{16}$ Appendix A4. shows that the gains are significantly different from each other for sufficiently distant experience groups and that the gain of the most experienced investor group is different from those of all other groups at the $1 \%$ level.

[Figure 2 about here]

[Table 4 about here]

longer time period. Results do not depend on this choice, though. We transform nominal return expectations into real expectations using the median inflation forecast from the Survey of Professional Forecasters. To be consistent with our asset pricing model, which models capital gain expectations, we transform real return expectations into a measure of real price growth expectations using the identity $R_{t+1}=\frac{P_{t+1}}{P_{t}}+\frac{D_{t+1}}{P_{t}}=$ $\frac{P_{t+1}}{P_{t}}+\beta^{D} \frac{D_{t}}{P_{t}}$ where $\beta^{D}$ denotes the expected gross quarterly real growth rate of dividends that we set equal to its sample average, i.e, $\beta^{D}=1.0048$, see table 1 . Results are very similar when using alternative plausible values for $\beta^{D}$. Also, since the UBS survey does not have a panel structure, the figure is based on a pseudo panel and reports at each point in time the median expectation of the considered experience group.

${ }^{16}$ Standard errors in table 4 and the p-values reported in appendix A4. are computed in a standard way, exploiting the fact that the procedure used for estimating the gain is a nonlinear least squares estimation. 


\section{The Asset Pricing Model}

This section presents the asset pricing model that we use to replicate the empirical facts documented in the previous section. We consider a model with a unit mass of atomistic investors who trade on a competitive stock market, where trade may be subject to a linear transactions tax. At the beginning of each period, stocks pay a stochastic dividend $D_{t}$ per unit and investors earn an exogenous wage income $W_{t}$. Income from both sources takes the form of perishable consumption goods.

There are $I \geq 1$ types of investors in the economy and a mass $\mu^{i}>0$ of each type $i \in\{0, \ldots, I\}$, where $\sum_{i=1}^{I} \mu_{i}=1$. Types differ with respect to the beliefs they entertain about the behavior of future stock prices and with regard to their accumulated stockholdings. For the special case without a financial transactions tax and when there is a single investor type, the setup reduces to the one studied in Adam, Marcet and Beutel (2015).

The Investment Problem. The representative investor of type $i \in\{1, \ldots, I\}$ solves

$$
\begin{aligned}
& \max _{\left\{C_{t}^{i} \geq 0, S_{t}^{i}\right\}_{t=0}^{\infty}} E_{0}^{\mathcal{P}^{i}} \sum_{t=0}^{\infty} \delta^{t} \frac{\left(C_{t}^{i}\right)^{1-\gamma}}{1-\gamma} \\
& \text { s.t.: } S_{t}^{i} P_{t}+C_{t}^{i}=S_{t-1}^{i}\left(P_{t}+D_{t}\right)+W_{t}-\tau\left|\left(S_{t}^{i}-S_{t-1}^{i}\right) P_{t}\right|+T_{t}^{i} \\
& \quad S_{-1}^{i} \text { given, }
\end{aligned}
$$

where $C^{i}$ denotes consumption, $\gamma>1$ the coefficient of relative risk aversion, $S^{i}$ the agent's stockholdings, $P \geq 0$ the (ex-dividend) price of the stock, $\tau \geq 0$ a linear financial transactions tax, which is levied on the agents' trading volume $\left|\left(S_{t}^{i}-S_{t-1}^{i}\right) P_{t}\right|$ and $T^{i} \geq 0$ lump sum tax rebates.

Investors' choices are contingent on the history of variables that are exogenous to their decision problem, i.e., time $t$ choices depend on $\left\{P_{j}, D_{j}, W_{j}, T_{j}\right\}_{j=0}^{t}$ and the initial condition $S_{-1}^{i}$. $\mathcal{P}^{i}$ denotes a subjective probability measure, which assigns probabilities to all possible infinite histories $\left\{P_{t}, D_{t}, W_{t}, T_{t}\right\}_{t=0}^{\infty}$. The agent's subjective probabilities may or may not coincide with the objective probabilities, i.e., agents may not know the true probabilities characterizing the behavior of the variables $\left\{P_{t}, D_{t}, W_{t}, T_{t}\right\}_{t=0}^{\infty}$, which are beyond their control, but agents are 'internally rational' in the sense of Adam and Marcet (2011), i.e., behave optimally given their beliefs about exogenous variables.

We consider linear transaction taxes because they are most easily implemented in practice. In addition, non-linear transaction taxes would create incentives to either partition trades into smaller increments or bundle trades of several investors into larger packages, so 
as to economize on transaction costs. The resulting tax rate would effectively be linear again. To simplify the analysis, we also assume that transaction taxes paid by investors of type $i$ are rebated in the same period in a lump sum fashion, i.e.,

$$
T_{t}^{i}=\tau\left|\left(S_{t}^{i}-S_{t-1}^{i}\right) P_{t}\right|
$$

where $S_{t}^{i}$ and $S_{t-1}^{i}$ on the r.h.s. of the previous equation denote the choices of the representative investor of type $i{ }^{17}$ We thereby eliminate the income effects associated with raising transaction taxes. ${ }^{18}$ We have also considered the case without tax rebates and appendix A5. shows that the main quantitative result are robust to assuming instead that taxes are not rebated to investors $\left(T_{t}^{i} \equiv 0\right.$ for all $\left.t, i\right)$.

The exogenous wage and dividend processes take the form considered previously in Adam, Marcet and Beutel (2015), with dividends evolving according to

$$
\ln D_{t}=\ln \beta^{D}+\ln D_{t-1}+\ln \varepsilon_{t}^{D}
$$

where $\beta^{D} \geq 1$ denotes the mean growth rate of dividends and, $\ln \varepsilon_{t}^{D}$ an i.i.d. growth innovation described further below. The wage income process $W_{t}$ is chosen such that the resulting aggregate consumption process $C_{t}=W_{t}+D_{t}$ is empirically appealing. ${ }^{19}$ In particular, we assume

$$
\ln W_{t}=\ln \rho+\ln D_{t}+\ln \varepsilon_{t}^{W},
$$

where

$$
\left(\begin{array}{c}
\ln \varepsilon_{t}^{D} \\
\ln \varepsilon_{t}^{W}
\end{array}\right) \sim i i N\left(-\frac{1}{2}\left(\begin{array}{c}
\sigma_{D}^{2} \\
\sigma_{W}^{2}
\end{array}\right),\left(\begin{array}{cc}
\sigma_{D}^{2} & \sigma_{D W} \\
\sigma_{D W} & \sigma_{W}^{2}
\end{array}\right)\right)
$$

which implies $E \varepsilon_{t}^{D}=E \varepsilon_{t}^{W}=1$.

Substituting the constraint into the objective function and dividing the objective function by $D_{0}^{1-\gamma}$, the investor's problem can be written as

$$
\begin{aligned}
& \max _{\left\{S_{t}^{i}\right\}_{t=0}^{\infty}} E_{0}^{\mathcal{P}^{i}} \sum_{t=0}^{\infty} \delta^{t}\left(\frac{D_{t}}{D_{0}}\right)^{1-\gamma} \frac{\left(S_{t-1}^{i}\left(\frac{P_{t}}{D_{t}}+1\right)+\frac{W_{t}+T_{t}^{i}}{D_{t}}-\tau\left|\frac{\left(S_{t}^{i}-S_{t-1}^{i}\right) P_{t}}{D_{t}}\right|-S_{t}^{i} \frac{P_{t}}{D_{t}}\right)^{1-\gamma}}{1-\gamma} \\
& \text { s.t. : } S_{-1}^{i} \text { given }
\end{aligned}
$$

\footnotetext{
${ }^{17}$ Agents' fully understand that what matters for tax rebates is the trading decision of the representative investor of type $i$ and not their own decision.

${ }^{18}$ Alternative assumptions, e.g., a rebate that is identical across investors at each point in time, would make rebates dependent on the whole distribution of trades in equilibrium and thus on the distribution of investors' beliefs. This would add many additional state variables into investors' decision problem.

${ }^{19}$ For further details, we refer the reader to Adam, Marcet and Beutel (2015), section 4.
} 
Due to the linear transaction cost specification, the preceding optimization problem fails to be differentiable. We explain in section 4.1. how we deal with this difficulty.

Subjective Beliefs. To complete the description of the investment problem we now specify investors' subjective probability measure $\mathcal{P}^{i}$. We first assume that agents know the processes (4) and (5), i.e., hold rational dividend and wage expectations. ${ }^{20}$ In a second step, we seek to specify subjective price beliefs in a way that allows us to capture the extrapolative nature of price expectations, as implied by survey data. In particular, following Adam, Marcet and Beutel (2015), we set up a belief system for prices that leads to expectation dynamics of the kind described by equation (1), which captures the empirical behavior of survey expectations. To this end, we endow agents with a belief system that allows for persistent deviations of the growth rate of prices from the growth rate of dividends. Specifically, we assume that agent $i$ 's perceived law of motion of prices is given by

$$
\ln P_{t+1}-\ln P_{t}=\ln \beta_{t+1}^{i}+\ln \varepsilon_{t+2}^{1, i}+\ln \varepsilon_{t+1}^{2, i}
$$

where $\varepsilon_{t+2}^{1, i}, \varepsilon_{t+1}^{2, i}$ denote (not directly observable) transitory shocks to price growth and $\beta_{t+1}^{i}$ a persistent price growth component that slowly drifts over time according to

$$
\ln \beta_{t+1}^{i}=\ln \beta_{t}^{i}+\ln \nu_{t+1}^{i}
$$

and where the persistent component of price growth $\ln \beta_{t+1}^{i}$ is also unobserved. The setup just described can capture periods with sustained increases in the price dividend ratio $\left(\beta_{t+1}^{i}>\right.$ $\left.\beta^{D}\right)$, as well as periods with sustained decreases $\left(\beta_{t+1}^{i}<\beta^{D}\right)$. The perceived innovations $\ln \varepsilon_{t+2}^{1, i}, \ln \varepsilon_{t+1}^{2, i}$ and $\ln v_{t+1}^{i}$ are assumed to be jointly normally distributed according to

$$
\left(\begin{array}{l}
\ln \varepsilon_{t+2}^{1, i} \\
\ln \varepsilon_{t+1}^{2, i} \\
\ln \nu_{t+1}^{i}
\end{array}\right) \sim i i N\left(\left(\begin{array}{c}
-\frac{\sigma_{\varepsilon, 1}^{2}}{2} \\
-\frac{\sigma_{\varepsilon, 2}^{2}}{2} \\
-\frac{\left(\sigma_{v}^{i}\right)^{2}}{2}
\end{array}\right),\left(\begin{array}{ccc}
\sigma_{\varepsilon, 1}^{2} & 0 & 0 \\
0 & \sigma_{\varepsilon, 2}^{2} & 0 \\
0 & 0 & \sigma_{\nu}^{i 2}
\end{array}\right)\right)
$$

where the variances $\sigma_{\varepsilon, 1}^{2}, \sigma_{\varepsilon, 2}^{2}$ of the transitory components are identical for all agents. We allow the perceived variance of the innovation to the persistent component $\left(\sigma_{\nu}^{i 2}\right)$ to differ across investors, so as to be able to capture the different responsiveness of survey expectations to realized price growth rates, as documented in section 3.3..

\footnotetext{
${ }^{20}$ This is motivated by the fact that wihtin the present setting with time separable preferences, (reasonable amounts of) extrapolation of wage and dividend beliefs would add very little to price volatility. This holds true for models with rational price expectations, as discussed in section 2 in Adam, Marcet and Beutel (2015), but also for models with subjective price beliefs, see for example section V.A in Adam, Marcet and Nicolini (2015).
} 
The previous setup defines an optimal filtering problem for agents, in which they need to decompose observed price growth $\left(\ln P_{t+1}-\ln P_{t}\right)$ into its persistent and transitory components $\left(\ln \beta_{t+1}^{i}\right.$ and $\ln \varepsilon_{t+2}^{1, i}+\ln \varepsilon_{t+1}^{2, i}$, respectively). In the special case, that the two transitory shock components are both unobserved and can thus be combined to $\ln \varepsilon_{t}^{i}=\ln \varepsilon_{t+1}^{1, i}+\ln \varepsilon_{t}^{2, i}$ with variance $\sigma_{\varepsilon}^{2}=\sigma_{\varepsilon, 1}^{2}+\sigma_{\varepsilon, 2}^{2}$, Adam, Marcet and Beutel (2015) show, that under the assumption of a normal prior with variance equal to its Kalman filter steady state value, price growth beliefs can be summarized by a single state variable $m_{t}^{i}$ that evolves according to

$$
\begin{aligned}
\ln m_{t}^{i} & =\ln m_{t-1}^{i}-\frac{\left(\sigma_{v}^{i}\right)^{2}}{2} \\
& +g^{i}\left(\ln P_{t}-\ln P_{t-1}+\frac{\left(\sigma_{\varepsilon}^{i}\right)^{2}+\left(\sigma_{v}^{i}\right)^{2}}{2}-\ln m_{t-1}^{i}\right) \\
g^{i} & =\frac{\left(\sigma^{i}\right)^{2}}{\sigma_{\varepsilon}^{2}}
\end{aligned}
$$

where

$$
\left(\sigma^{i}\right)^{2} \equiv \frac{-\left(\sigma_{\nu}^{i}\right)^{2}+\sqrt{\left(\left(\sigma_{\nu}^{i}\right)^{2}\right)^{2}+4\left(\sigma_{\nu}^{i}\right)^{2} \sigma_{\varepsilon}^{2}}}{2}
$$

is the Kalman filter steady state variance. The state variable $\ln m_{t}^{i}$ describes the mean of $\ln \beta_{t}^{i}$ conditional on the information available at time $t$, i.e., $\ln \beta_{t}^{i}$ is conditionally $N\left(\ln m_{t}^{i},\left(\sigma^{i}\right)^{2}\right)$ distributed, which implies

$$
E_{t}^{\mathcal{P}^{i}}\left[\frac{P_{t+1}}{P_{t}}\right]=m_{t}^{i} e^{\left(\sigma^{i}\right)^{2} / 2} .
$$

This previous result, together with equation (11) shows that optimal belief updating delivers - up to a log-exponential transformation - the updating equation (1) considered in the empirical section. Moreover, equation (12) shows that the optimal updating parameter $g^{i}$ is a positive function of the variance $\left(\sigma_{\nu}^{i}\right)^{2}$, which allows us to replicate the empirically observed heterogeneity in the belief updating equations.

To avoid simultaneity between prices and price beliefs, which may give rise to multiple market clearing price and price belief pairs, we shall rely on a slightly modified information structure, where agents observe $\ln \varepsilon_{t}^{1, i}$ as part of their time $t$ information set. Adam, Marcet and Beutel (2015) show how such a modified information structure gives rise to an updating equation of the form

$$
\ln m_{t}^{i}=\ln m_{t-1}^{i}+g^{i}\left(\ln P_{t-1}-\ln P_{t-2}-\ln m_{t-1}^{i}\right)-g \ln \varepsilon_{t}^{1, i}
$$

which has lagged price growth enter. ${ }^{21}$

\footnotetext{
${ }^{21}$ Price growth expectations are then given by $E_{t}^{\mathcal{P}^{i}}\left[P_{t+1} / P_{t}\right]=m_{t}^{i}$.
} 
To complete the description of the belief system, we need to specify investors' beliefs about the behavior of the lump sum tax rebate $T_{t}^{i}$. We shall assume that agents understand that the tax rebates do not depend on their own decision, instead on the choices of the representative investor of the same type $i$. Moreover, we assume that agents know the tax rebate function $(3) .^{22}$

Market Clearing. The stock market clearing condition is given by

$$
\sum_{i=1}^{I} S_{t}^{i} \mu_{i}=1+u_{t}
$$

where the left-hand side denotes total stock demand by investors of all types and the righthand side total stock supply. We incorporate a small exogenous stochastic component $u_{t}$ into stock supply, which we assume to be white noise, uniformly distributed and to have support $[-\bar{u}, \bar{u}]$ for some $\bar{u}>0$ sufficiently close to zero. Stock supply shocks $u_{t}$ thereby capture the issuance of new stocks and stock repurchases by firms. ${ }^{23}$ We add these shocks because linear financial transaction taxes lead to piecewise price-insensitive demand curves, which can give rise to equilibrium price indeterminacy in the absence of supply shocks. In our numerical applications, we make sure that $\bar{u}$ is sufficiently small such that it has no noticeable effects on the outcomes that emerge in the absence of a financial transaction tax. For the case with transaction taxes, the supply shock effectively only selects the equilibrium price whenever price-insenstitive demand curve may create the potential for price indeterminacy.

\subsection{Solution Approach}

This section explains how one can solve for the optimal solution of the non-differentiable problem (7). The approach we pursue consists of defining an alternative optimization problem with a differentiable transaction cost specification, so that a standard solution approach based on first order conditions can be applied. The alternative problem has the property that all choices that are feasible in the original problem are also feasible in the alternative problem. Therefore, if the optimal solution to the differentiable problem is a feasible choice in (7), then it must also solve (7).

\footnotetext{
${ }^{22}$ This assumption considerably simplifies the analysis: since in equilibrium individual actions coincide with those of the representative investor of the same type, we do not need to incorporate any additional state variables that characterize the future evolution of lump sum taxes, when writing a recursive representation of the agents' decision problem.

${ }^{23}$ Alternatively, they capture changes to asset float, as discussed in Ofek and Richardson (2003) and Hong, Scheinkman, and Xiong (2006).
} 
The alternative problem we consider is

$$
\begin{aligned}
& \max _{\left\{S_{t}^{i}\right\}_{t=0}^{\infty}} E_{0}^{\mathcal{P}^{i}} \sum_{t=0}^{\infty} \delta^{t}\left(\frac{D_{t}}{D_{0}}\right)^{1-\gamma} \frac{\left(S_{t-1}^{i}\left(\frac{P_{t}}{D_{t}}+1\right)+\frac{W_{t}+T_{t}^{i}}{D_{t}}-\tau_{t}^{i} \frac{\left(S_{t}^{i}-S_{t-1}^{i}\right) P_{t}}{D_{t}}-S_{t}^{i} \frac{P_{t}}{D_{t}}\right)^{1-\gamma}}{1-\gamma} \\
& \text { s.t. : } S_{-1}^{i} \text { given }
\end{aligned}
$$

where $\tau_{t}^{i} \in[-\tau, \tau]$ denotes a state-contingent but fully linear transaction tax/subsidy and where $T_{t}^{i}$ is given by (3). Problem (14) is differentiable and can be solved in a standard way using first-order conditions. Moreover, since $\tau_{t}^{i} \in[-\tau, \tau]$, all stockholding plans that are feasible in the original problem (7) continue to be feasible in the alternative problem (14).

Suppose that the state-contingent transactions cost function $\tau_{t}^{i}$ and the associated optimal stockholding plan $\left\{S_{t}^{i, o p t}\right\}_{t=0}^{\infty}$ solving (14) jointly satisfy for all $t \geq 0$ the following property

$$
\begin{array}{ll}
\tau_{t}^{i}=\tau & \text { at contingencies where } S_{t}^{i, o p t}>S_{t-1}^{i, o p t} \\
\tau_{t}^{i}=-\tau & \text { at contingencies where } S_{t}^{i, o p t}<S_{t-1}^{i, o p t} \\
\tau_{t}^{i} \in[-\tau, \tau] & \text { at contingencies where } S_{t}^{i, o p t}=S_{t-1}^{i, o p t},
\end{array}
$$

then $\left\{S_{t}^{i, o p t}\right\}_{t=0}^{\infty}$ is also feasible in the original problem (7) and thus the solution to (7). The task of solving the original non-differentiable problem (7) is thus equivalent to finding a state contingent tax function $\tau_{t}^{i}$ such that condition (15) holds for the optimal solution of the alternative differentiable problem (14).

For a given $\left\{\tau_{t}^{i}\right\}_{t=0}^{\infty}$ the solution to (14) is characterized by the first order condition

$$
\left(\frac{C_{t}}{D_{t}}\right)^{-\gamma}\left(1+\tau_{t}^{i}\right) \frac{P_{t}}{D_{t}}=\delta E_{t}^{P}\left(\frac{C_{t+1}}{D_{t+1}}\right)^{-\gamma}\left(\frac{D_{t+1}}{D_{t}}\right)^{1-\gamma}\left(\frac{P_{t+1}}{D_{t+1}}\left(1+\tau_{t+1}^{i}\right)+1\right)
$$

As noted above, investor $i$ 's subjective beliefs can be summarized by the recursively evolving state variable $m_{t}^{i}$. Provided the state contingency of the tax function can be expressed in the form $\tau_{t}^{i}=\tau^{i}\left(S_{t-1}^{i}, \frac{P_{t}}{D_{t}}, \frac{W_{t}}{D_{t}}, m_{t}^{i}\right)$, where the arguments in the function should be interpreted as the choices and beliefs of the representative agent of type $i$, the optimal stock holding policy then also has a recursive representation of the form $S_{t}=S^{i}\left(S_{t-1}^{i}, \frac{P_{t}}{D_{t}}, \frac{W_{t}}{D_{t}}, m_{t}^{i}\right)$, by the same arguments as put forward in Adam, Marcet and Beutel (2015). ${ }^{24,25}$

Our numerical solution routines, which are described in appendix A2. simultaneously solve for the functions $\tau^{i}(\cdot)$ and $S^{i}(\cdot)$ that jointly satisfy equations (15) and (16). Numerically

\footnotetext{
${ }^{24}$ The fact that the transaction costs are linear and that under the stated assumptions the tax rebate $T^{i}$ is a function of the same state variables is key for this result.

${ }^{25}$ The fact that $\tau_{t}^{i}$ depends on $S_{t-1}^{i}$ is just a convenient way to summarize dependence of the tax function on past values of $P_{t}, D_{t}$ and $W_{t}$. It does not mean that the agent thinks that $\tau_{t}^{i}$ depends on its own choices, in fact, as should be clear from the first order condition (16), the agent takes $\tau_{t}^{i}$ as exogenously given.
} 
solving for the optimal solution is computationally costly. Despite extensive reliance on parallelization, the numerical computation of the solution and the evaluation of the Euler errors takes around 30 hours of computing time.

\section{Outcomes under Objective Price Beliefs}

Before presenting the model outcome under subjective price beliefs, this section briefly discusses the model predictions for the case where agents hold rational price expectations. With objective price beliefs and with investors holding identical initial stock endowments, differences between investor types disappear. The model then reduces to a representative agent rational expectations model with time separable preferences. As shown in Adam, Marcet and Beutel (2015), the pricing implications of the model then display a well-known set of shortcomings. The standard deviation of the price dividend ratio, for instance, is one order of magnitude below that observed in the data and displays virtually no persistence over time. The model thus fails to replicate the large and protracted run-ups and reversals that can be observed for the PD ratio in U.S. data. The model also fails to replicate the positive correlation between the $\mathrm{PD}$ ratio and expected returns, as evidenced in survey data. Finally, with rational price expectations, the model does not give rise to trade in equilibrium, thus cannot be related to the documented facts on trading activity. As we show in the next section, model performance strongly improves, once one incorporates the kind of extrapolative behavior documented in survey data.

\section{Quantitative Model Performance}

This section evaluates the quantitative performance of our asset pricing model in the absence of FTTs with subjective price beliefs given by equations (8) and (9). Performance is evaluated in terms of the ability to match the stylized facts presented in section 3.. The effects of introducing FTTs will be studied in section 8 ..

We parameterize our model using the model parameters employed in Adam, Marcet and Beutel (2015), which are summarized in table 5. Table 5 also lists the value for the support of stock supply shocks, which is a new parameter and set such that the amount of trade caused by these shocks amounts to less than $0.3 \%$ of the average trading volume in a setting without FTTs. Since trading volume is only weakly affected for the considered range of FTTs, the same holds approximately true for the case with FTTs. Furthermore, we verify that in the absence of FTTs, stock supply shocks affect the model moments in almost non-noticable ways. 
Motivated by the evidence in table 4, we consider a model with 5 agent types, each of which has mass $1 / 5$, and assign to them the point estimates of the updating gains from table $4 .^{26}$

[Table 5 about here]

Table 6 compares the model generated moments in the absence of FTTs to those in the data. $^{27}$ The model moments for our baseline calibration are reported in the third column, while the fourth column reports the associated t-ratios for each considered moment. ${ }^{28}$ Overall, our asset pricing model does a good job in replicating the pure stock price moments, i.e., the first five moments reported in the table. It matches particularly well the mean and autocorrelation of the PD ratio, as well as the mean of quarterly real stock returns. It produces, however, too much volatility for the $\mathrm{PD}$ ratio and for returns. The model also does a good job in capturing the observed high positive correlation between the PD ratio and average return expectations in the survey data $\left(\operatorname{corr}\left(P D_{t}, \bar{E}_{t} R_{t+1}\right)\right)$.

Regarding the newly added moments, the model generates a high positive autocorrelation in trading volume $\left(\operatorname{corr}\left(T V_{t}, T V_{t-1}\right)\right)$, albeit the model correlation is too high relative to the one found in the data. The model also manages to quantitatively capture the positive correlation between trading volume and absolute price changes $\left(\operatorname{corr}\left(T V_{t},\left|P_{t} / P_{t-1}-1\right|\right)\right)$. When looking at the correlation between trading volume and the $\mathrm{PD}$ ratio $\left(\operatorname{corr}\left(T V_{t}, P D_{t}\right)\right)$, the model produces a fairly weak positive correlation, but one that is stronger than in the data. The model also generates a positive correlation between trading volume and cross sectional dispersion of return expectations $\left(\operatorname{corr}\left(T V_{t}, \operatorname{st}\left(\widetilde{E}_{t}^{i} R_{t+1}\right)\right)\right)$, but again overstates this correlation relative to the data. ${ }^{29}$ The latter should not be surprising, given that in our simple model belief dispersion is the only reason why agents want to trade.

Since the baseline model produces an 'anti-puzzle' in the form of too much stock price volatility relative to the data, we also consider a model version in which we dampen the

\footnotetext{
${ }^{26}$ Recall that we chose the experience groups in table 4 so as to have approximately the same number of investors in each group.

${ }^{27}$ All simulation results are based on 100.000 quarters of simulated data, where the first 10.000 quarters are considered as a burn-in and discarded when calculating model moments. Also, to make results from different simulations more comparable, we use fixed sequences for the exogenous driving processes (wages, dividends, stock supply shocks).

${ }^{28}$ The t-ratio is based on an estimate of the standard deviation of the data moment as a measure of uncertainty, where we estimate the standard deviation of the moment in the data using standard procedures, as described - for example - in Adam, Marcet and Nicolini (2015).

${ }^{29}$ The data moment reported in table 6 is the one pertaining to the UBS survey, which has also been used to compute $\operatorname{corr}\left(P D_{t}, \bar{E}_{t} R_{t+1}\right)$ in the data.
} 
extrapolative component in belief updating. This is motivated by the fact that the updating gains in table 4 are themselves estimated with uncertainty. Specifically, we reduce the point estimates from table 4 by 2.5 times the estimated standard deviation of the point estimate ${ }^{30}$, leaving all other parameters unchanged. The resulting model moments are reported in the second to last column in table 6 below, with the last column reporting the associated t-ratios. Price and return volatility are now in line with data, while all other moments remain largely unaffected.

Overall, we find that the model does a good job in quantitatively replicating the joint behavior of stock price, trading volume and price expectations.

[Table 6 about here]

\section{Asset Price Booms and their Implications}

This section illustrates that stock prices in the model occasionally embark on a selfsustaining asset price boom and bust cycle. Unlike in the representative agent model of Adam, Marcet and Beutel (2015), such cycles have large welfare implications for different agent types.

[Figure 3 about here]

To illustrate the potential of the model to generate boom-bust cycles and to compute the welfare implications of such cycles, we conduct a simple controlled experiment using the baseline model from the previous section: we fix agents' initial stockholdings and initial beliefs at their ergodic sample means; we then shock the economy with $n$ positive dividend growth shocks of a two standard deviation size. Such or larger positive dividend shocks occur with a probability of about $2.5 \%$ per quarter. We shut down all other shocks, including dividend growth shocks after period $n$. We begin the experiment with $n=1$ and successively increase $n$ until we obtain a stock price boom and bust cycle from period $n+1$ onwards. Figure 3 depicts - for different values of $n$ - the equilibrium outcomes for the PD ratio. While the PD ratio reacts very little to the positive news for $n \leq 3$ (stock prices, however, do react to the positive dividend news), one obtains for $n=4$ a very large stock price boom

\footnotetext{
${ }^{30}$ We use for each gain parameter the gain specific standard deviation reported in the last row of table 4.
} 
and a subsequent price bust. ${ }^{31}$ The economic forces driving the boom and bust dynamics are explained in detail in Adam, Marcet and Beutel (2015). Here, we only note that the boom results from the fact that agents - having observed price increases - become optimistic about future price growth and eventually bid up stock prices by sufficient amounts, so that price increases and increasing optimism mutually reinforce each other. This effect is set in motion whenever a sufficient number of positive fundamental shocks, e.g., dividend growth shocks, occurs. The boom comes to an end, when agents' increased wealth leads them to eventually increase consumption demand, so that stock demand ceases to increase further with increased optimism. Prices then stagnate, which means that they fail to fulfill the high expectations of agents. Agents then revise beliefs downwards and set in motion a price bust. The bust causes a temporary undershooting of the PD ratio below its ergodic mean, but prices eventually return close to their ergodic mean absent further shocks, see figure 3.

[Figure 4 about here]

Figure 4 depicts the PD ratio (top panel) together with agents' equilibrium trading decisions (middle panel) and return expectations (bottom panel) for the boom-bust episode triggered by four positive dividend growth shocks. To increase readability of the graph, we only report the trading patterns and return expectations of agents with the highest and lowest updating gain parameters. ${ }^{32}$ In the UBS survey, high gains were estimated for agents with few years of stock market experience, while the most experienced group displayed a low updating gain. For this reason we refer to agents with a high (low) gain as inexperienced (experienced) agents.

Figure 4 shows that in the initial phase of the stock price boom, inexperienced agents do rather well. They start buying stocks early on and well before prices approach their peak value. Experienced investors sell assets during the boom phase, i.e., much too early. Yet, once the PD ratio is high, inexperienced investors are much more optimistic about future returns than experienced investors, see the bottom panel. As a result, inexperienced investors continue buying stocks from low gain types at high prices (relative to dividends). Also, inexperienced investors continue buying during much of the price bust phase and only sell in significant amounts once the PD ratio started undershooting its long-run mean. Thus, even though inexperienced investors are doing well initially, this fails to be the case over the entire boom-bust cycle.

\footnotetext{
${ }^{31}$ Increasing $n$ further would lead to very similar boom-bust dynamics as for the case with $n=4$.

${ }^{32}$ Agents types with intermediate updating gain values take intermediate decisions that are in between those shown in the figure.
} 
To gauge the welfare effects of a boom-bust episode, we compare the outcome in figure 4 to a situation in which the same shocks occur, but where agents hold their beliefs constant at the initial value, i.e., do not respond to the price movements triggered by the dividend growth shocks, so that there is no asset price boom. We can then compute the permanent proportional consumption variation that would make (ex-post realized) utility in the setting with constant beliefs and without an asset price boom identical to the (ex-post realized) utility in the setting with the asset price boom shown in figure 4. Outcomes are reported in table 7, which shows that asset price booms are extremely costly for inexperienced agents and extremely beneficial for experienced investors: the welfare equivalent consumption variations of a boom-bust episode amount to a permanent change in consumption of several percentage points.

[Table 7 about here]

\section{The Effects of Financial Transaction Taxes}

We now consider the implications of introducing linear financial transaction taxes, focusing on the implication of FTTs for the behavior of asset pricing moments, the patterns of boom-bust dynamics and trading volume.

Table 8 reports how the asset pricing moments from the baseline model in table 6 are affected by various tax rates. The main effect of financial transaction taxes consists of increasing asset price volatility, as measured by the standard deviation of quarterly stock returns $\left(\operatorname{std}\left(r^{s}\right)\right)$ and the standard deviation of the PD ratio $(\operatorname{std}(P D)) .{ }^{33}$ Except for the reduced correlation between trading volume and prices $\left(\operatorname{corr}\left(T V_{t}, P D_{t}\right), \operatorname{corr}\left(T V_{t}, \mid P_{t} / P_{t-1}-\right.\right.$ $1 \mid)$ ), the remaining asset pricing moments from table 6 prove to be rather robust towards the introduction of FTTs.

The last four rows in table 8 report a number of additional statistics about asset price boom-bust episodes and trading volume. These statistics allow to asses in greater detail why asset price volatility increases with the introduction of FTTs. The fourth to last row in table 8, for example, reports the number of asset price boom episodes per 100 years of simulated data, where we define the beginning of a boom as the first time in which the quarterly PD ratio exceeds a level of 250 and the end of a boom as the first time it falls

\footnotetext{
${ }^{33}$ For very high tax rates $(10 \%)$ the volatility of the PD ratio starts to fall, while return volatility continues to increase. We discuss this issue further below.
} 
below 200 thereafter. ${ }^{34}$ The results in the table show that the number of stock price booms is monotonically increasing in the FTTs, with boom-bust episodes becoming about a third more likely relative to the case without transaction taxes when the tax rate reaches $4 \%$.

The third and second to last rows in table 8 display, respectively, information about the length of the boom episodes and the average peak value of the PD reached during these episodes. It shows that booms tend to become shorter lived and somewhat less pronounced as the tax rate rises, but these effects are not very strong for tax rates up to $4 \%$. As a result, the effect of an increased number of booms dominates and the standard deviation of the PD ratio increases with the tax rate. For a $10 \%$ tax rate, the decrease in the peak level of the $\mathrm{PD}$ during booms and the reduced length of stock price booms start to dominate, causing the standard deviation of the PD ratio to decreases, even if the standard deviation of returns still increases.

Somewhat surprisingly, the average trading volume (relative to the case without FTTs) tends to increase with the level of FTTs. As we discuss further below, this occurs because there is more trade during booms times, as belief disagreements are then larger, and because booms become more likely with the introduction of FTTs.

\section{[Table 8 about here]}

Table 9 reports the welfare implications associated with introducing different tax rates. Starting from the ergodic mean for stock holdings and beliefs in the no-tax economy, the table reports the welfare equivalent permanent consumption variation that would make different agent types in the economy with taxes as well-off in expected terms as in the economy without taxes. ${ }^{35}$ Table 9 clearly shows that agents that extrapolate more, i.e., inexperienced investors in our survey sample, tend to lose, while more experienced investors tend to win in expected terms. ${ }^{36}$ For all agent types, except the median type, whose utility is largely unaffected by the tax rate, the gains and losses monotonically increase with the tax rate. Wealth redistribution between investors thus increases with the tax rate.

[Table 9 about here]

\footnotetext{
${ }^{34}$ The reported numbers are very robust to choosing different thresholds because boom-bust episodes are periods in which prices display a clearly distinct behavior.

${ }^{35}$ We use objective probabilities to compute agents' expected utility.

${ }^{36}$ The welfare effects in table 9 are smaller than those reported in table 7 . The latter reports the effects of a single stock price boom episode relative to the counterfactual outcome without a boom. Since booms are (in expected terms) not likely to occur within the immediate future, when starting the simulation at the ergodic mean, the welfare effects in table 9 are not as large as those reported in table 7 .
} 
Table 10 provides additional insights by reporting asset price moments conditional on being in a boom period, as defined above, and conditional on being in 'normal times', i.e., periods that are not identified as boom periods. Clearly, the PD ratio is considerably higher during boom times and so is the standard deviation of the PD ratio. Mean quarterly stock returns during boom periods are considerably higher than in normal times, but stock returns also display a considerably larger standard deviation. Furthermore, while the introduction of FTTs reduces the volatility of the PD ratio and returns during boom periods, FTTs increase both of these standard deviations during normal times. As we show below, it is precisely the increase in volatility during normal times coupled with extrapolative behavior which causes stock price booms to become more likely.

Table 10 shows that trading volume decreases with the size of the FTT during boom periods, but - somewhat paradoxically - increases during normal times. Upon closer inspection, we find that for tax rates up to $4 \%$ the increase in trading volume during normal times is purely driven by post-boom trading activity. As can be seen from figure 4, trading activity stays high long after the PD ratio returned to values below 200. Once one removes these post-boom periods from the normal times, trading volume is actually decreasing with the FTTs in normal times. ${ }^{37}$

[Table 10 about here]

To illustrate further how FTTs increase the likelihood of boom-bust cycles, we now perform a similar experiment as carried out in section 7 . for the case without a tax. Specifically, we consider the model with a FTT of $4 \%$ and fix initial stockholdings and initial beliefs at their ergodic sample means. We then shock the economy with $n \geq 0$ positive dividend growth shocks of two standard deviations. Yet, this time we continue to let the small exogenous stock supply shocks operate at all times. These shocks are themselves not enough to generate stock price booms, but can do so in combination with dividend shocks.

[Figures 5 and 6 about here]

Figure 5 depicts the probability that the economy embarks on a stock price boom as a function of the number of dividend growth shocks, integrating over possible realizations of the

\footnotetext{
${ }^{37}$ The situation is different for very high tax rates (10\%). Trading activity then increases also during normal times, even when excluding post-boom periods. This occurs because the large increase in price volatility leads to an amount of belief disagreement and thus trade in normal times, which more than compensates the trade-reducing effect of the tax.
} 
stock supply shocks. ${ }^{38}$ For the case without a FTT, booms start to emerge once $n$ increases above $4 .{ }^{39}$ The situation differs for the case with a $4 \%$ FTT, where fewer fundamental shocks are required to start a boom episode. For $n \leq 1$, the economy never embarks on a stock price boom, but for $n=2$ stock price booms emerge in more than $60 \%$ of the cases and for $n \geq 3$ virtually always. This shows that booms become more likely in a situation with FTTs, as fewer fundamental shocks are required to set it in motion.

Figure 6 illustrates the driving force giving rise to this outcome. The figure depicts the stock demand function for a $4 \% \mathrm{FTT}^{40}$ It shows that around the level of prior stockholding (assumed to be equal to one), stock demand (shown on the vertical axis) is not sensitive to the stock price (shown on the horizontal axis). This price insensitivity of stock demand covers a considerable price range and is actually increasing with the tax rate. ${ }^{41}$ Therefore, in the presence of FTTs, even very small exogenous variations in stock supply can lead to large movements in realized prices, explaining why prices become more volatile during 'normal times'. Since agents use realized price growth to update price expectations, FTTs increase the likelihood that stock prices embark on a belief-driven stock price boom.

\section{State-Contingent Financial Transaction Taxes}

Motivated by the results in the previous section, this section considers the effects of introducing state-contingent transaction taxes that are only levied once the PD ratio exceeds a certain (sufficiently high) threshold value $\overline{P D}$. The idea behind such a state-contingent tax is that it avoids the increase in price volatility during 'normal times', thereby avoiding that the stock market embarks with higher likelihood on a boom-bust cycle, while potentially limiting the duration and extent of stock price booms once they have taken hold.

Specifically, consider a setting with linear transaction taxes $\tau>0$, which are levied only if $P D_{t} \geq \overline{P D}$, and zero taxes otherwise. We set the threshold value $\overline{P D}$ equal to 250 , which is the value used to identify the beginning of a stock price boom episodes in previous sections. After solving for the optimal stock demand functions ${ }^{42}$, it turns out that state-contingent

\footnotetext{
${ }^{38}$ As before, we define a boom as a stituation where the PD ratio subsequently increases above 250 at some point. We consider up to 12 quarters after the last dividend shock. Results prove very robust to choosing different thresholds and period limits. Probabilities are computed from averaging the outcome of 500 stochastic realizations.

${ }^{39}$ Since we now let stock supply shocks also operate in the case without a tax, this shows that the findings of figure 3 are robust to the introduction of the stock supply shock.

${ }^{40}$ The figure assumes $\tau=4 \%$ and the following values for the state variables: $W_{t} / D_{t}=\rho, m_{t}=\beta^{D}$, and $S_{-1}=1$.

${ }^{41}$ Appendix A3. explains how one can accurately determine the inaction regions.

${ }^{42}$ The solution strategy outlined in section 4.1. for the case with a non-state contingent tax can then still
} 
taxes lead to problems of non-existence of equilibrium prices, as well as to the possibility of equilibrium multiplicities.

The non-existence problem is illustrated in figure 7, which depicts the excess stock demand (on the vertical axis) as a function of the price dividend ratio (horizontal axis). The figure depicts these functions for all agent types, as well as the aggregate excess demand function. $^{43}$

Figure 7 shows that once the $\mathrm{PD}$ ratio exceeds its critical value $\overline{P D}$, agents want to buy or sell less stocks, i.e., the excess demand functions discontinuously jump to a value closer to the no trade line (the zero line). As a result, the aggregate excess demand function also has a jump at $P D=\overline{P D}$ and for the case depicted in figure 7 , this leads to non-existence of an equilibrium price: the excess demand function is strictly positive for $P D<\overline{P D}$ but strictly negative for $P D \geq \overline{P D}$.

Obviously, the jump in the aggregate excess stock demand function does not necessarily have to be of the kind shown in figure 7 . We also encountered cases in which there was an upward jump at the critical value $\overline{P D}$. This can happen whenever agents who seek to sell stocks respond more to the tax once its levied than agents who want to purchase stocks. Figure 8 depicts an example, where the aggregate excess demand jumps upwards at $P D=\overline{P D}$. As the figure illustrates, this can give rise to multiple market clearing equilibrium prices. Since realized prices feed into agents' price beliefs, price multiplicities have the potential to significantly increase price volatility.

While the non-existence problem could possibly be overcome by introducing taxes that are a continuous function of the $\mathrm{PD}$ ratio, the multiplicity issue is harder to address. One would have to design state-contingent taxes in such a way that aggregate stock excess demand functions are never upward sloping in the vicinity of the zero point. It is unclear which tax design would be able to achieve this outcome.

[Figure 7 and 8 about here]

be applied because the tax function $\tau^{i}\left(S_{t-1}^{i}, \frac{P_{t}}{D_{t}}, \frac{W_{t}}{D_{t}}, m_{t}^{i}\right)$ derived in section 4.1. can already depend on the $\mathrm{PD}$ ratio. Instead of satisfying equations (15) and (16), the tax function and the stock holding policy must now jointly satisfy the first order condition (16) and

$$
\begin{array}{ll}
\tau_{t}^{i}=\tau & \text { at contingencies where } S_{t}^{i, o p t}>S_{t-1}^{i, o p t} \text { and } P D \geq \overline{P D} \\
\tau_{t}^{i}=-\tau & \text { at contingencies where } S_{t}^{i, o p t}<S_{t-1}^{i, o p t} \text { and } P D \geq \overline{P D} \\
\tau_{t}^{i} \in[-\tau, \tau] & \text { at contingencies where } S_{t}^{i, o p t}=S_{t-1}^{i, o p t} \text { and } P D \geq \overline{P D} \\
\tau_{t}^{i}=0 & \text { otherwise, }
\end{array}
$$

so as to be feasible in the original problem with a non-differentiable tax function (above the PD threshold).

${ }^{43}$ To illustrate the effects in the most transparent way, we use the setting with a $10 \%$ transaction tax, but the effects are qualitatively the same for lower tax rates. 


\section{Conclusions}

We present a quantitatively credible asset pricing model in which stock prices display occasional boom and bust cycles in valuation, which redistribute large amounts of wealth between different investor types. We show how the introduction of financial transactions taxes increases price volatility during 'normal times' and thereby the likelihood that the stock market embarks on a belief-driven boom and bust cycle. State-contingent transaction taxes, which seek to avoid the increase in price volatility during normal times, generate problems via equilibrium multiplicities and non-existence. Taken together, these findings cast serious doubts on whether financial transaction taxes can fruitfully contribute towards increasing the efficiency of stock market prices and transactions.

A key channel highlighted by the present framework is that empirically plausible degrees of extrapolation by investors make it important that market interventions do not increase stock price volatility during normal times, i.e., outside boom-bust episodes. Throughout the analysis, we have taken the degree of extrapolation as given. Conceivably, market interventions can also have a direct effect on the degree to which investors extrapolate past capital gains. To the extent that FTTs reduce extrapolation, FTTs can generate additional benefits that are not captured within the present analysis and may overturn our results. Obviously, if FTTs give rise to more extrapolation, they generate additional costs and strengthen the point made in the present paper. Empirically investigating the effects of FTTs on the degree of investor extrapolation thus appears to be an interesting avenue for future research. 


\section{A Appendix}

\section{A1. Data sources}

Stock price data: Our stock price data is for the United States and has been downloaded from 'The Global Financial Database'. ${ }^{44}$ The period covered is Q1:1949-Q1:2012. The nominal stock price series is the "'SP 500 Composite Price Index (w/GFD extension)"' (Global Fin code "'_SPXD"'). The daily series has been transformed into quarterly data by taking the index value of the last day of the considered quarter. To obtain real values, nominal variables have been deflated using the 'USA BLS Consumer Price Index' (Global Fin code 'CPUSAM'). The monthly price series has been transformed into a quarterly series by taking the index value of the last month of the considered quarter. Nominal dividends have been computed as follows

$$
D_{t}=\left(\frac{I^{D}(t) / I^{D}(t-1)}{I^{N D}(t) / I^{N D}(t-1)}-1\right) I^{N D}(t)
$$

where $I^{N D}$ denotes the "SP 500 Composite Price Index (w/GFD extension)"' described above and $I^{D}$ is the "'SP 500 Total Return Index (w/GFD extension)"' (Global Fin code "“_SPXTRD"'), which contains returns from price changes and dividend payouts. In the notation of our model, $I^{D}(t)$ is equal to $P_{t}$ and $I^{N D}(t) / I^{N D}(t-1)$ equal to $\left(P_{t}+D_{t}\right) / P_{t-1}$. We first computed monthly dividends and then quarterly dividends by adding up the monthly series. Following Campbell (2003), dividends have been deseasonalized by taking averages of the actual dividend payments over the current and preceding three quarters.

Stock market survey data: The UBS survey is the UBS Index of Investor Optimism. ${ }^{45}$ For all our calculations we use own portfolio return expectations from 1999:Q1 to 2007:Q2. We do not use data from 1998 due to missing values. The micro dataset of the UBS survey consists of 92823 record. Data-cleaning results in the removal of 18379 this records: Following Vissing-Jorgensen (2003), we ignore survey responses with stated expected returns larger than $95 \%$ in absolute value, which results in the elimination of 16380 observations. Furthermore, we ignore records, where the difference between the respondent's age and his stated stock market experience is less than 16 years, which eliminates $2378 .{ }^{46}$

The Shiller survey covers individual investors and has been kindly made available to us by Robert Shiller at Yale University. The survey spans the period 1999:Q1-2012:Q4. The

\footnotetext{
${ }^{44}$ It is available at http://www.globalfinancialdata.com.

${ }^{45}$ See http://www.ropercenter.uconn.edu/data_access/data/datasets/ubs_investor.html.

${ }^{46}$ The two numbers do not add up to 18379 , since some records satisfy both criteria for elimination.
} 
CFO survey is collected by Duke University and CFO magazine and collects responses from about 450 CFOs. The data span the period 2000:Q3-2012:Q4.

Inflation expectations data: The Survey of Professional Forecasters (SPF) is available from the Federal Reserve Bank of Philadelphia.

Trading volume: We have daily data from Thomson Reuters Financial Datastream from 2nd January 1973 until 31st March 2014. We look at the series "'US-DS Market"' (TOTMKUS), an index of 1000 U.S. stocks traded on NYSE and Nasdaq.

We compute quarterly trading volume as follows: Starting from daily trading volume (DS: VA) and daily market value (DS: MV) we compute daily trading volume (VA/MV), i.e. the share of the market that is traded on each day. We then aggregate this up, following Lo and Wang (2009), by summing the shares over all trading days in the quarter, thus arriving at the share of the market that is traded in a particular quarter up to the last trading day of the quarter (end of March, June, September, December). Thus volume is measured over the same time period where expectations are measured. Moreover, end of quarter PDs are associated with the trading volume accumulated in the preceding 3 months.

\section{A2. Numerical solution approach}

We now describe the solution strategy for determining the functions $S^{i}(\cdot)$ and $\tau^{i}(\cdot)$ and the associated lump sum rebate $T^{i}(\cdot)$. To simplify notation we drop all $i$ superscripts. Also, instead of solving for the optimal stockholding function $S(\cdot)$, we solve in our numerical approach for the optimal consumption dividend ratio $C_{t} / D_{t}=C D\left(S_{t-1}, \frac{P_{t}}{D_{t}}, \frac{W_{t}}{D_{t}}, m_{t}\right)$. There is a one-to-one mapping between the $S(\cdot)$ policy and the $C D(\cdot)$ policy due to the flow budget constraint, which implies

$$
\frac{C_{t}}{D_{t}}=S_{t-1}\left(\frac{P_{t}}{D_{t}}+1\right)+\frac{W_{t}+T_{t}}{D_{t}}-\tau_{t}\left(S_{t}-S_{t-1}\right) \frac{P_{t}}{D_{t}}-S_{t} \frac{P_{t}}{D_{t}}
$$

and due to the assumption that $\tau_{t}=\tau\left(S_{t-1}, \frac{P_{t}}{D_{t}}, \frac{W_{t}}{D_{t}}, m_{t}^{i}\right)$ and $T_{t} / D_{t}=\tau\left|\left(S_{t}-S_{t-1}\right) P_{t} / D_{t}\right|$.

We solve the first order condition by combining time iteration with an endogenous grid point method, thereby avoiding any root finding steps in the solution procedure. This considerably speeds up the numerical solution. We now describe this procedure in detail.

We start with a guess for the future consumption policy $C D^{(j)}(\cdot)$, the transactions tax function $\tau^{(j)}(\cdot)$ and the lump sum rebate relative to dividends $T D^{(j)}(\cdot)=T^{j}(\cdot) / D_{t}$, where the superscript $(j)$ denotes the $j$-th guess in the time iteration procedure and where all functions depend on the arguments $\left(S_{t-1}, \frac{P_{t}}{D_{t}}, \frac{W_{t}}{D_{t}}, m_{t}\right)$.

Given the guesses $C D^{(j)}(\cdot), \tau^{(j)}(\cdot)$ and $T D^{(j)}(\cdot)$ and given an alternative grid of current 
values $\left(S_{t}, \frac{P_{t}}{D_{t}}, \frac{W_{t}}{D_{t}}, m_{t}\right)$ - note this alternative grid contains $S_{t}$ not $S_{t-1}$ - we can compute the updated consumption policy $\widetilde{C D}^{(j+1)}\left(S_{t}, \frac{P_{t}}{D_{t}}, \frac{W_{t}}{D_{t}}, m_{t}\right)$ and the updated marginal tax function $\widetilde{\tau}^{(j+1)}$, which are both defined over the alternative grid, by iterating on the FOC (16). In particular, equation (16) implies

$$
\left(\widetilde{C D}^{(j+1)}\right)^{-\gamma}\left(1+\widetilde{\tau}_{t}^{(j+1)}\right)=\frac{\delta E_{t}^{\mathcal{P}}\left(C D^{(j)}\right)^{-\gamma}\left(\frac{D_{t+1}}{D_{t}}\right)^{1-\gamma}\left(\frac{P_{t+1}}{D_{t+1}}\left(1+\tau_{t+1}^{(j)}\right)+1\right)}{P_{t} / D_{t}}
$$

Given any point $\left(S_{t}, \frac{P_{t}}{D_{t}}, \frac{W_{t}}{D_{t}}, m_{t}\right)$ on the alternative grid, we can compute the distribution over future (standard) grid points $\left(S_{t}, \frac{P_{t+1}}{D_{t+1}}, \frac{W_{t+1}}{D_{t+1}}, m_{t+1}\right)$, using the perceived evolution over prices, dividends, wages and beliefs. Together with the guesses $C D^{(j)}(\cdot)$ and $\tau^{(j)}$, this allows evaluating the r.h.s. of (17) using a standard numerical integration method (we use deterministic integration based on quadrature points). For future reference, let $M\left(S_{t}, \frac{P_{t}}{D_{t}}, \frac{W_{t}}{D_{t}}, m_{t}\right)$ denote the value of the r.h.s. of (17). The l.h.s. of equation (17) then implies that we have also determined the value of the product $\left(C_{t} / D_{t}\right)^{1-\gamma}\left(1-\tau_{t}\right)$, at every alternative grid point.

It now remains to compute the updated functions $C D^{(j+1)}, \tau_{t}^{(j+1)}$ and $T D^{(j+1)}$ which are defined over the standard grid $\left(S_{t-1}, \frac{P_{t}}{D_{t}}, \frac{W_{t}}{D_{t}}, m_{t}\right)$. We do so by fixing an arbitrary alternative $\operatorname{grid}$ point $\left(S_{t}^{*},\left(\frac{P_{t}}{D_{t}}\right)^{*},\left(\frac{W_{t}}{D_{t}}\right)^{*}, m_{t}^{*}\right)$ and by checking the range of possible situations $S_{t-1} \lessgtr S_{t}^{*}$.

We begin by conjecturing $S_{t-1}=S_{t}^{*}$. The flow budget constraint then determines the implied consumption dividend ratio, i.e.,

$$
\frac{C_{t}}{D_{t}}=S_{t}^{*}+\left(\frac{W_{t}}{D_{t}}\right)^{*}
$$

We can then check whether the tax rate $\tau_{t}^{(j+1)}$ associated with (18), defined as

$$
\left(\frac{C_{t}}{D_{t}}\right)^{-\gamma}\left(1+\tau_{t}^{(j+1)}\right)=M\left(S_{t}^{*},\left(\frac{P_{t}}{D_{t}}\right)^{*},\left(\frac{W_{t}}{D_{t}}\right)^{*}, m_{t}^{*}\right)
$$

satisfies $\tau_{t}^{(j+1)} \in[-\tau,+\tau]$. If so, then we have found the optimal consumption dividend ratio $C D^{(j+1)}$ and associated shadow tax rate $\tau_{t}^{(j+1)}$ at the standard grid point $\left(S_{t-1}=S_{t}^{*},\left(\frac{P_{t}}{D_{t}}\right)^{*},\left(\frac{W_{t}}{D_{t}}\right)^{*}, m_{t}^{*}\right)$. The updated lump sum tax rebate over dividends at this gridpoint is simply $T D^{(j+1)}=0$.

If the value of $\tau_{t}^{(j+1)}$ solving (19) satisfies $\tau_{t}^{(j+1)}>\tau$, then it must be that $S_{t}^{*}>S_{t-1} \cdot{ }^{47} \mathrm{We}$ therefore set $\tau_{t}^{(j+1)}=\tau$ and determine the equilibrium consumption dividend ratio $C D^{(j+1)}$

\footnotetext{
${ }^{47}$ Reducing $\tau_{t}$ so that it satisfies $\tau_{t} \leq \tau$ requires that $\left(C_{t} / D_{t}\right)^{-\gamma}$ increases, see the l.h.s. of equation (17). From the flow budget constraint follows that this can only happen if $S_{t-1}$ decreases below $S_{t}^{*}$, given the values for $\left(P_{t} / D_{t}\right)^{*}$ and $\left(W_{t} / D_{t}\right)^{*}$.
} 
from equation (17), which delivers

$$
\left(C D^{(j+1)}\right)^{-\gamma}(1+\tau)=M\left(S_{t}^{*},\left(\frac{P_{t}}{D_{t}}\right)^{*},\left(\frac{W_{t}}{D_{t}}\right)^{*}, m_{t}^{*}\right)
$$

Finally, we use the budget constraint to compute the associated initial grid point $S_{t-1}$, which must solve

$$
C D^{(j+1)}=S_{t-1}\left(\left(\frac{P_{t}}{D_{t}}\right)^{*}+1\right)+\left(\frac{W_{t}}{D_{t}}\right)^{*}-S_{t}^{*}\left(\frac{P_{t}}{D_{t}}\right)^{*}
$$

where we used the updated lump sum rebate function $T D^{(j+1)}=\tau \cdot\left(S_{t}^{*}-S_{t-1}\right)\left(\frac{P_{t}}{D_{t}}\right)^{*}$. We have thus determined $C D^{(j+1)}, \tau^{(j+1)}$ and $T D^{(j+1)}$ at the grid point $\left(S_{t-1},\left(\frac{P_{t}}{D_{t}}\right)^{*},\left(\frac{W_{t}}{D_{t}}\right)^{*}, m_{t}^{*}\right)$.

If the value of $\tau_{t}^{(j+1)}$ solving (19) satisfies $\tau_{t}^{(j+1)}<-\tau$, then we must assume $S_{t}^{*}<S_{t-1}$ and thus set $\tau_{t}^{(j+1)}=-\tau$. Using (17) we can determine the equilibrium consumption dividend ratio $C D^{(j+1)}$

$$
u^{\prime}\left(C D^{(j+1)}\right)(1-\tau)=M\left(S_{t}^{*},\left(\frac{P_{t}}{D_{t}}\right)^{*},\left(\frac{W_{t}}{D_{t}}\right)^{*}, m_{t}^{*}\right) .
$$

Again, we use the budget constraint to compute the associated grid point $S_{t-1}$, which must solve

$$
C D^{(j+1)}=S_{t-1}\left(\left(\frac{P_{t}}{D_{t}}\right)^{*}+1\right)+\left(\frac{W_{t}}{D_{t}}\right)^{*}-S_{t}^{*}\left(\frac{P_{t}}{D_{t}}\right)^{*}
$$

where we use the updated lump sum rebate function $T D^{(j+1)}=-\tau \cdot\left(S_{t}^{*}-S_{t-1}\right)\left(\frac{P_{t}}{D_{t}}\right)^{*}$

We perform the iterations described above until convergence of the functions $C D^{(j)}(\cdot)$, $\tau^{(j)}(\cdot)$ and $T D^{(j)}$.

\section{A3. Inaction Regions and Adaptive Grid Point Choice}

A transaction tax leads to partially flat stock demand curves (inaction regions) and thereby introduces a high degree of nonlinearity - non-differentiabilities in the $\frac{P_{t}}{D_{t}}$-dimension - into the consumption policy function $C D^{(j)}(\cdot)$ and the associated shadow tax $\tau^{(j)}(\cdot)$. While linear interpolation between two grid points yields very accurate approximations of these functions for most $\frac{P_{t}}{D_{t}}$ values, this is generally not true close to the boundaries of the inaction regions, if these boundaries are not elements of our discretized state space.

Including the $\frac{P_{t}}{D_{t}}$ boundaries of the inaction region into the discretized state space poses two challenges: First, the exact locations of these boundaries are not known a priori, but depend on the optimal solution. Therefore, the $\frac{P_{t}}{D_{t}}$ grid is required to change in every iteration. We describe in the sequel how we use an adaptive grid point choice to ensure 
that our best guess for the inaction region boundaries is always part of the $\frac{P_{t}}{D_{t}}$ grid. Second, these boundaries are not independent of other states, but vary with $\left(S_{t-1}, \frac{W_{t}}{D_{t}}, m_{t}\right)$. Hence, the $\frac{P_{t}}{D_{t}}$ grid is not only required to change in every iteration of the algorithm, but also to be dependent on other state variables. ${ }^{48}$ We clarify below how we interpolate our policy to states not contained in the discretized state space.

Adaptive grid points: Since the non-differentiability problem only occurs in the $\frac{P_{t}}{D_{t}}$ dimension, we fix a vector $\left(S_{t-1}, \frac{W_{t}}{D_{t}}, m_{t}\right)$ in the sequel. First, we observe, that the interior of the inaction region in the $\frac{P_{t}}{D_{t}}$-dimension can be identified by the shadow tax function $\tau(\cdot)$ : The optimal consumption (or, equivalently, stock holding) policy does not change in a neighborhood of the current value of $\frac{P_{t}}{D_{t}}$, if and only if $\tau\left(S_{t-1}, \frac{P_{t}}{D_{t}}, \frac{W_{t}}{D_{t}}, m_{t}\right) \in(-\tau, \tau)$. Since in such cases $S_{t-1}=S_{t}$, the same relationship must hold for the function $\tilde{\tau}$ defined on the alternative "state space" $\left(S_{t}, \frac{P_{t}}{D_{t}}, \frac{W_{t}}{D_{t}}, m_{t}\right)$. In our solution algorithm, we solve for this function $\tilde{\tau}$ by solving equation (19) under the assumption that consumption satisfies the no trade relationship (18) and set it to $\tau$, whenever its value exceeds $\tau$ and to $-\tau$, whenever its value is less than $-\tau$. The boundaries of the inaction region are therefore given for those values of $\frac{P_{t}}{D_{t}}$, for which no trade consumption defined by (18) and $\tau_{t}^{(j+1)} \in\{-\tau, \tau\}$ solve equation (19). This yields two equations

$$
\left(S_{t}^{*}+\left(\frac{W_{t}}{D_{t}}\right)^{*}\right)^{-\gamma}(1 \pm \tau)=M\left(S_{t}^{*},\left(\frac{P}{D}\right)_{ \pm},\left(\frac{W_{t}}{D_{t}}\right)^{*}, m_{t}^{*}\right)
$$

which we solve for the adapted grid points $\left(\frac{P}{D}\right)_{ \pm}$in each iteration of the above algorithm. ${ }^{49}$ We make sure, that in our algorithm not only the functions $C D^{(j)}(\cdot), \tau^{(j)}(\cdot)$ and $T D^{(j)}$, but also these adapted grid points converge. The present approach is similar to the approach proposed in Brumm and Grill (2014). The latter cover the discretized state space with simplices and look for 'just binding' constraints on each edge of these simplices. We only look at edges that are orthogonal to the $\left(S_{t-1}, \frac{W_{t}}{D_{t}}, m_{t}\right)$-hyperplane, which is computationally more efficient within the present setup.

Interpolation: We fix the set of initial grid points $G_{S}, G_{W D}, G_{P D}, G_{m}$ for the state space. Our discretized state space is, however, not given by the product $G_{S} \times G_{W D} \times G_{P D} \times$

\footnotetext{
${ }^{48}$ Including all inaction boundaries for any combination of $\left(S_{t-1}, \frac{W_{t}}{D_{t}}, m_{t}\right)$ into a common $\frac{P_{t}}{D_{t}}$ grid creates a computationally prohibitively large number of discretization points.

${ }^{49}$ Note, that $\left(\frac{P}{D}\right)_{+}$and $\left(\frac{P}{D}\right)_{-}$are functions of $\left(\left(S_{t}^{*},\left(\frac{W_{t}}{D_{t}}\right)^{*}, m_{t}^{*}\right)\right.$, although this is suppressed in our notation.
} 
$G_{m}$, but instead by

$$
\begin{aligned}
& G_{S} \times G_{W D} \times G_{P D} \times G_{m} \\
& \cup\left\{\left(S, W D, P D_{+}(S, W D, m), m\right) \mid(S, W D, m) \in G_{S} \times G_{W D} \times G_{m}\right\} \\
& \cup\left\{\left(S, W D, P D_{-}(S, W D, m), m\right) \mid(S, W D, m) \in G_{S} \times G_{W D} \times G_{m}\right\}
\end{aligned}
$$

The standard linear interpolation method on a Cartesian product of one-dimensional grids is therefore augmented as follows: for a given query point $\left(S_{q}, W D_{q}, P D_{q}, m_{q}\right)$, we first search for indices $i, j, k$, such that $S_{q} \in\left[S_{i}, S_{i+1}\right], W D_{q} \in\left[W D_{j}, W D_{j+1}\right]$ and $m_{q} \in\left[m_{k}, m_{k+1}\right]$ and then linearly interpolate the policy in the $P D$-dimension for each combination $(S, W D, m) \in$ $\left\{S_{i}, S_{i+1}\right\} \times\left\{W D_{j}, W D_{j+1}\right\} \times\left\{m_{k}, m_{k+1}\right\}$ using as a PD grid the intersection of the discretized state space with the line parallel to the $P D$-axis that crosses $(S, W D, m)$. This yields eight interpolated policy values $C D_{u, v, w}$ with $(u, v, w) \in\{i, i+1\} \times\{j, j+1\} \times\{k, k+1\}$ of the function

$$
(S, W D, m) \mapsto C D\left(S, W D, P D_{q}, m\right)
$$

at the chosen closest $(S, W D, m)$-grid points. We then use ordinary three-dimensional linear interpolation to obtain the interpolated policy value for $C D\left(S_{q}, W D_{q}, P D_{q}, m_{q}\right)$, i.e.

$$
\begin{aligned}
& C D^{\text {interp }}\left(S_{q}, W D_{q}, P D_{q}, m_{q}\right) \\
& =\sum_{u=i, i+1} \sum_{v=j, j+1} \sum_{w=k, k+1} \frac{\left|S_{q}-S_{u}\right|\left|W D_{q}-W D_{v}\right|\left|m_{q}-m_{w}\right|}{\left(S_{i+1}-S_{i}\right)\left(W D_{j+1}-W D_{j}\right)\left(m_{k+1}-m_{k}\right)} C D_{u, v, w}
\end{aligned}
$$

We proceed analogously for linear extrapolation.

\section{A4. Testing for Equality of Gain Estimates in Table 4}

Table A.1 reports the p-values for the null hypothesis $H_{0}: g^{i}=g^{j}$ for $i \neq j$.

[Table A.1 about here ]

\section{A5. No Tax Rebates}

Table A.2 reports the outcomes shown in table 8 in the main text for the case where tax revenue is not rebated to investors $\left(T_{t}^{i}=0\right.$ for all $\left.t, i\right)$. It shows that findings a robust to making this alternative assumption on tax rebates. 
[Table A.2 about here]

\section{References}

Adam, K., And A. Marcet (2011): "Internal Rationality, Imperfect Market Knowledge and Asset Prices," Journal of Economic Theory, 146, 1224-1252.

Adam, K., A. Marcet, and J. Beutel (2015): "Stock Price Booms and Expected Capital Gains," University of Mannheim mimeo.

Adam, K., A. Marcet, and J. P. Nicolini (2015): "Stock Market Volatility and Learning," Journal of Finance (forthcoming).

Aiyagari, S. R., and M. Gertler (1991): "Asset Returns with Transactions Costs and Uninsured Individual Risk," Journal of Monetary Economics, 27(3), 311-331.

Brumm, J., and M. Grill (2014): "Computing Equilibria in Dynamic Models with Occasionally Binding Constraints," Journal of Economic Dynamics and Control, 38, 142-160.

Brunnermeier, M., and S. Nagel (2004): "Hedge Funds and the Technology Bubble," Journal of Finance, 59, 2013-2040.

Buss, A., B. Dumas, R. Uppal, and G. Vilkov (2013): "Comparing Different Regulatory Measures to Control Stock Market Volatility: A General Equilibrium Analysis," available at ramanuppal.com.

Campbell, J. Y. (2003): "Consumption-Based Asset Pricing," in Handbook of Economics and Finance, ed. by G. M. Constantinides, M. Harris, and R. Stulz, pp. 803-887. Elsevier, Amsterdam.

Coelho, M. (2014): "Dodging Robin Hood: Responses to Fracne and Italy's Financial Transaction Taxes," Berkeley University Mimeo.

Colliard, J.-E., and P. Hoffmann (2015): "Financial Transaction Taxes, Market Composition, and Liquidity," HEC Paris mimeo.

Constantinides, G. M. (1986): "Capital Market Equilibrium with Transaction Costs," Journal of Political Economy, 94, 842-862. 
Dumas, B., A. Kurshev, and R. Uppal (2009): "Equilibrium Portfolio Strategies in the Presence of Sentiment Risk and Excess Volatility," Journal of Finance, 64, 579-629.

DÁvila, E. (2013): "Optimal Financial Transaction Taxes," Harvard University mimeo.

Froot, K. A., And M. Obstfeld (1991): "Intrinsic Bubbles: The Case of Stock Prices," Amercian Economic Review, 81, 1189-1214.

Guasoni, P., And J. Muhle-Karbe (2013): "Portfolio Choice with Transaction Costs: A User's Guide," in Paris-Princeton Lecturs on Mathematical Finance 2013. Springer.

HaU, H. (1998): "Competitive Entry and Endogenous Risk in the Foreign Exchange Market," Review of Financial Studies, 11, 757-787.

(2006): "The Role of Transaction Costs for Financial Volatility: Evidence from the Paris Bourse," Journal of the European Economic Association, 4, 862-890.

Heaton, J., and D. J. LuCas (1996): "Evaluating the Effects of Incomplete Markets on Risk Sharing and Asset Pricing," Journal of Political Economy, pp. 443-487.

Hong, H., J. Scheinkman, and W. Xiong (2006): "Asset Float and Speculative Bubbles," Journal of Finance, 61, 1073-1117.

Hong, H., And J. C. Stein (2007): "Disagreement and the Stock Market," Journal of Economic Perspectives, 21, 109-128.

Jeanne, O., And A. K. Rose (2002): "Noise Trading and Exchange Rate Regimes," Quarterly Journal of Economics, 117, 537-569.

Jones, C. M., And P. J. Seguin (1997): "Transactions Costs and Price Volatility: Evidence from Commission Deregulation," American Economic Review, 87, 728-737.

Karpoff, J. M. (1987): "The Relation Between Price Changes and Trading Volume: A Survey," Journal of Financial and Quantitative Analysis, 22, 109-126.

Lo, A. W., And J. Wang (2009): "Stock Market Trading Volume," in Handbook of Financial Econometrics, Vol. 2: Applications, ed. by Y. Ait-Sahalia, and L. P. Hansen. NorthHolland.

Malmendier, U., and S. Nagel (2011): "Depression Babies: Do Macroeconomic Experiences Affect Risk Taking," Quarterly Journal of Economics, 126, 373-416. 
McCulloch, N., and G. Pacillo (2011): "A Tobin Tax: A Review of the Evidence," Institute of Development Studies Research Report No. 68.

Ofek, E., and M. Richardson (2003): "Dotcom Mania: The Rise and Fall of Internet Stock Prices," Journal of Finance, 58, 1113-1137.

Roy, R., and R. Cléroux (1993): "Vector Cross-Correlations in Time Series and Applications," International Statistical Review, 61, 447-464.

Scheinkman, J. A., and W. Xiong (2003): "Overconfidence and Speculative Bubbles," Journal of Political Economy, 111, 1183-1220.

Simsek, A. (2013): "Speculation and Risk Sharing with New Financial Assets," Quarterly Journal of Economics, p. 1365 Ü1396.

Tobin, J. (1978): "A Proposal for International Monetary Reform," Eastern Economic Journal, 4, 153-159.

Umlauf, S. R. (1993): "Transaction Taxes and the Behavior of the Swedish Stock Market," Journal of Financial Economics, 33, 227-240.

Vayanos, D., And J. Wang (2014): "Market Liquidity - Theory and Empirical Evidence," Handbook of the Economics of Finance (forthcoming).

Vissing-Jorgensen, A. (2003): "Perspectives on Behavioral Finance: Does "Irrationality" Disappear with Wealth? Evidence from Expectations and Actions," in 2003 Macroeconomics Annual, Boston. NBER. 


\begin{tabular}{|l|c|}
\hline & $\begin{array}{c}\text { U.S. Data } \\
\text { 1949:Q1-2012:Q1 }\end{array}$ \\
\hline Stock prices: & \\
$E[P D]$ & 139.7 \\
$\operatorname{std}(P D)$ & 65.3 \\
$\operatorname{corr}\left(P D_{t}, P D_{t-1}\right)$ & 0.98 \\
$\operatorname{std}\left(r^{s}\right)$ & $8.01 \%$ \\
$E\left[r^{s}\right]$ & $1.89 \%$ \\
\hline Survey expectations: & \\
$\operatorname{corr}\left(P D_{t}, \bar{E}_{t} R_{t+1}\right)$ & 0.79 \\
\hline $\operatorname{Dividends:}$ & \\
$E\left[D_{t} / D_{t-1}-1\right]$ & $0.48 \%$ \\
$\operatorname{std}\left(D_{t} / D_{t-1}\right)$ & $1.92 \%$ \\
\hline
\end{tabular}

Table 1: Quarterly stock prices, dividends and survey expectations

\begin{tabular}{|l|l|l|l|l|}
\hline & \multicolumn{4}{|c|}{ Detrending Method } \\
& Baseline (linear) & \multicolumn{1}{|c|}{ Linear-quadratic } & HP filter & MA \\
\hline $\operatorname{corr}\left(T V_{t}, T V_{t-1}\right)$ & $0.89^{* * *}$ & $0.88^{* * *}$ & $0.66^{* * *}$ & $0.43^{* * *}$ \\
$\operatorname{corr}\left(T V_{t}, P D_{t}\right)$ & -0.07 & 0.01 & -0.03 & -0.06 \\
$\operatorname{corr}\left(T V_{t},\left|P_{t} / P_{t-1}-1\right|\right)$ & $0.34^{* * *}$ & $0.33^{* * *}$ & $0.33^{* * *}$ & $0.23^{* * *}$ \\
\hline
\end{tabular}

Table 2: Trading Volume and Price Behavior 
Detrending Method

\begin{tabular}{|c|c|c|c|c|}
\hline & eline (linear) & Linear-quadratic & HP filter & MA \\
\hline \multicolumn{5}{|c|}{ UBS-Gallup Survey (1-year horizon) } \\
\hline $\operatorname{corr}\left(T V_{t}, \operatorname{std}\left(\widetilde{E}_{t}^{i} R_{t+1}\right)\right)$ & $0.41^{*}$ & $0.41^{* *}$ & $0.43^{*}$ & 0.17 \\
\hline $\operatorname{corr}\left(T V_{t}, I Q R\left(\widetilde{E}_{t}^{i} R_{t+1}\right)\right)$ & 0.36 & $0.50^{*}$ & $0.65^{* *}$ & $0.41^{* *}$ \\
\hline \multicolumn{5}{|c|}{ Shiller Survey (3-months horizon) } \\
\hline $\operatorname{corr}\left(T V_{t}, \operatorname{std}\left(\widetilde{E}_{t}^{i} R_{t+1}\right)\right)$ & $0.37^{*}$ & $0.40^{*}$ & $0.43^{* *}$ & -0.06 \\
\hline $\operatorname{corr}\left(T V_{t}, I Q R\left(\widetilde{E}_{t}^{i} R_{t+1}\right)\right)$ & $0.52^{* *}$ & $0.54^{* *}$ & $0.63^{* * *}$ & 0.19 \\
\hline \multicolumn{5}{|c|}{ Shiller Survey (6-months horizon) } \\
\hline $\operatorname{corr}\left(T V_{t}, \operatorname{std}\left(\widetilde{E}_{t}^{i} R_{t+1}\right)\right)$ & $0.60 * * *$ & $0.60^{*}$ & $0.58^{* * *}$ & 0.03 \\
\hline $\operatorname{corr}\left(T V_{t}, I Q R\left(\widetilde{E}_{t}^{i} R_{t+1}\right)\right)$ & $0.43^{*}$ & $0.46^{*}$ & $0.47^{* *}$ & 0.09 \\
\hline \multicolumn{5}{|c|}{ Shiller Survey (1-year horizon) } \\
\hline $\operatorname{corr}\left(T V_{t}, \operatorname{std}\left(\widetilde{E}_{t}^{i} R_{t+1}\right)\right)$ & $0.51^{* *}$ & $0.52^{* *}$ & $0.51^{* * *}$ & 0.18 \\
\hline $\operatorname{corr}\left(T V_{t}, I Q R\left(\widetilde{E}_{t}^{i} R_{t+1}\right)\right)$ & $0.49^{* *}$ & $0.55^{* *}$ & $0.56^{* * *}$ & 0.23 \\
\hline \multicolumn{5}{|c|}{ CFO Survey (1-year horizon) } \\
\hline $\operatorname{corr}\left(T V_{t}, \operatorname{std}\left(\widetilde{E}_{t}^{i} R_{t+1}\right)\right)$ & $0.70^{* *}$ & $0.65^{* *}$ & $0.64^{* * *}$ & -0.02 \\
\hline
\end{tabular}

*/** $/{ }^{* * *}$ indicates significance at the $10 \% / 5 \% / 1 \%$ significance level, respectively.

Table 3: Trading volume and disagreement

\begin{tabular}{|l|ccccc|}
\hline Experience (yrs) & $0-5$ & $6-11$ & $12-17$ & $18-23$ & $>23$ \\
\hline Estimated $g^{i}$ & $\mathbf{0 . 0 3 1 6}$ & $\mathbf{0 . 0 2 8 6}$ & $\mathbf{0 . 0 2 6 4}$ & $\mathbf{0 . 0 2 3 0}$ & $\mathbf{0 . 0 1 8 0}$ \\
\hline (std. deviation) & $(0.0028)$ & $(0.0013)$ & $(0.0017)$ & $(0.0013)$ & $(0.0090)$ \\
\hline
\end{tabular}

Table 4: Estimated updating parameters 


\begin{tabular}{lll} 
Parameter & Value & Calibration Target \\
\hline$\beta^{D}$ & 1.0048 & average quarterly real dividend growth \\
$\sigma_{D}$ & 0.0192 & std. deviation quarterly real dividend growth \\
$\rho$ & 22 & average consumption-dividend ratio \\
$\sigma_{D W}$ & $-3.74 \cdot 10^{-4}$ & jointly chosen s.t. corr $_{t}\left(C_{t} / C_{t-1}, D_{t} / D_{t-1}\right)=0.2$ \\
$\sigma_{W}$ & 0.0197 & and $s t d_{t}\left(C_{t} / C_{t-1}\right)=\frac{1}{7} s t d_{t}\left(D_{t} / D_{t-1}\right)$ \\
$\sigma_{\varepsilon}$ & 0.0816 & std. deviation of quarterly real stock price growth \\
$\delta$ & 0.995 & average PD ratio \\
$\gamma$ & 2 & - none - \\
$\bar{u}$ & $1 \cdot 10^{-5}$ & - none - \\
\hline
\end{tabular}

Table 5: Model calibration

\begin{tabular}{|l|c|c|c|c|c|}
\hline & U.S. Data & $\begin{array}{c}\text { Baseline } \\
\text { Model } \\
\text { (no tax) }\end{array}$ & t-ratio & $\begin{array}{c}\text { Reduced } \\
\text { Gain } \\
\text { (no tax) }\end{array}$ & t-ratio \\
\hline$E[P D]$ & 139.77 & 135.77 & 0.16 & 117.16 & 0.91 \\
$\operatorname{std}(P D)$ & 65.17 & 122.13 & -3.84 & 92.96 & -1.88 \\
$\operatorname{corr}\left(P D_{t}, P D_{t-1}\right)$ & 0.98 & 0.98 & 0.84 & 0.98 & -0.13 \\
$\operatorname{std}\left(r^{s}\right)$ & $8.00 \%$ & $11.63 \%$ & -9.05 & $8.27 \%$ & -0.68 \\
$E\left[r^{s}\right]$ & $1.89 \%$ & $2.11 \%$ & -0.47 & $1.84 \%$ & 0.11 \\
$\operatorname{corr}\left(P D_{t}, E_{t} R_{t+1}\right)$ & 0.79 & 0.84 & -0.78 & 0.84 & -0.73 \\
$\operatorname{corr}\left(T V_{t}, T V_{t-1}\right)$ & 0.89 & 0.97 & -4.29 & 0.97 & -4.14 \\
$\operatorname{corr}\left(T V_{t}, P D_{t}\right)$ & -0.07 & 0.37 & -5.79 & 0.47 & -7.09 \\
$\operatorname{corr}\left(T V_{t},\left|P_{t} / P_{t-1}-1\right|\right)$ & 0.34 & 0.25 & 1.12 & 0.28 & 0.78 \\
$\operatorname{corr}\left(T V_{t}, \operatorname{st}\left(\widetilde{E}_{t}^{i} R_{t+1}\right)\right)$ & 0.41 & 0.95 & -3.67 & 0.92 & -3.50 \\
\hline
\end{tabular}

Table 6: Quantitative match of the asset pricing model

\begin{tabular}{|l|c|c|c|c|c|}
\hline Gain & 0.0316 & 0.0286 & 0.0264 & 0.0230 & 0.0180 \\
\hline Permanent cons. variation & $-7.01 \%$ & $-3.51 \%$ & $-1.27 \%$ & $1.73 \%$ & $5.24 \%$ \\
\hline
\end{tabular}

Table 7: Welfare cost of a stock price boom-bust episode 


\begin{tabular}{|l|c|c|c|c|c|}
\hline & No Tax & $1 \%$ Tax & $2 \%$ Tax & $4 \%$ Tax & $10 \%$ Tax \\
\hline$E[P D]$ & 135.77 & 137.21 & 139.74 & 142.47 & 146.27 \\
$\operatorname{std}(P D)$ & 122.13 & 123.18 & 125.42 & 127.10 & 125.24 \\
$\operatorname{corr}\left(P D_{t}, P D_{t-1}\right)$ & 0.98 & 0.98 & 0.98 & 0.98 & 0.98 \\
$\operatorname{std}\left(r^{s}\right)$ & $11.63 \%$ & $11.85 \%$ & $12.14 \%$ & $12.55 \%$ & $14.04 \%$ \\
$E\left[r^{s}\right]$ & $2.11 \%$ & $2.14 \%$ & $2.18 \%$ & $2.24 \%$ & $2.49 \%$ \\
$\operatorname{corr}\left(P D_{t}, E_{t} R_{t+1}\right)$ & 0.84 & 0.85 & 0.86 & 0.87 & 0.89 \\
$\operatorname{corr}\left(T V_{t}, T V_{t-1}\right)$ & 0.97 & 0.97 & 0.97 & 0.97 & 0.94 \\
$\operatorname{corr}\left(T V_{t}, P D_{t}\right)$ & 0.37 & 0.35 & 0.33 & 0.29 & 0.17 \\
$\operatorname{corr}\left(T V_{t},\left|P_{t} / P_{t-1}-1\right|\right)$ & 0.25 & 0.25 & 0.24 & 0.21 & 0.05 \\
$\operatorname{corr}\left(T V_{t}, s_{d}\left(\widetilde{E}_{t}^{i} R_{t+1}\right)\right)$ & 0.95 & 0.94 & 0.93 & 0.92 & 0.87 \\
\hline$\#$ of booms per 100 yrs ${ }^{*}$ & 1.82 & 1.95 & 2.12 & 2.40 & 3.06 \\
average boom length $(q u a r t e r s)^{*}$ & 32.42 & 31.87 & 31.41 & 30.44 & 27.21 \\
average boom peak $(\mathrm{PD})^{*}$ & 491.03 & 485.82 & 480.31 & 469.95 & 443.86 \\
$E[T V]$ relative to no tax & $100.00 \%$ & $99.64 \%$ & $101.49 \%$ & $102.52 \%$ & $117.85 \%$ \\
\hline${ }^{*}$ a boom starts in the first period in which the quarterly PD ratio exceeds a value of 250 and ends once it falls below 200. \\
\hline
\end{tabular}

Table 8: Effects of introducing financial transaction taxes

\begin{tabular}{|l|c|c|c|c|c|}
\hline Gain & 0.0316 & 0.0286 & 0.0264 & 0.0230 & 0.0180 \\
\hline $1 \% \operatorname{Tax}$ & $-0.34 \%$ & $-0.14 \%$ & $-0.02 \%$ & $0.06 \%$ & $0.25 \%$ \\
$2 \% \operatorname{Tax}$ & $-0.84 \%$ & $-0.36 \%$ & $-0.06 \%$ & $0.16 \%$ & $0.62 \%$ \\
$4 \% \operatorname{Tax}$ & $-1.56 \%$ & $-0.64 \%$ & $-0.07 \%$ & $0.28 \%$ & $1.18 \%$ \\
$10 \% \operatorname{Tax}$ & $-2.76 \%$ & $-1.00 \%$ & $0.10 \%$ & $0.39 \%$ & $2.15 \%$ \\
\hline
\end{tabular}

Table 9: Welfare implications of FTTs (welfare equiv. permanent cons. variations) 


\begin{tabular}{|l|c|c|c|c|c|}
\hline & No Tax & $1 \%$ Tax & $2 \%$ Tax & $4 \%$ Tax & $10 \%$ Tax \\
\hline$E[P D]$ & 424.63 & 419.79 & 415.04 & 406.56 & 384.06 \\
std $(P D)$ & 44.93 & 44.13 & 44.27 & 42.89 & 42.01 \\
$\operatorname{corr}\left(P D_{t}, P D_{t-1}\right)$ & 0.48 & 0.48 & 0.47 & 0.49 & 0.53 \\
$s t d\left(r^{s}\right)$ & $23.06 \%$ & $22.86 \%$ & $22.52 \%$ & $21.76 \%$ & $19.34 \%$ \\
$E\left[r^{s}\right]$ & $3.68 \%$ & $3.74 \%$ & $3.67 \%$ & $3.55 \%$ & $3.15 \%$ \\
$E[T V]$ rel. to no tax & $100.00 \%$ & $96.13 \%$ & $93.12 \%$ & $88.27 \%$ & $80.13 \%$ \\
\hline \multicolumn{5}{|c|}{ Normal times ${ }^{+}$} \\
\hline$E[P D]$ & 85.87 & 85.33 & 84.63 & 83.59 & 83.72 \\
$s t d(P D)$ & 15.37 & 15.89 & 16.68 & 18.14 & 23.62 \\
$\operatorname{corr}\left(P D_{t}, P D_{t-1}\right)$ & 0.84 & 0.84 & 0.85 & 0.85 & 0.86 \\
$s t d\left(r^{s}\right)$ & $8.15 \%$ & $8.36 \%$ & $8.65 \%$ & $9.31 \%$ & $12.26 \%$ \\
$E\left[r^{s}\right]$ & $1.84 \%$ & $1.84 \%$ & $1.88 \%$ & $1.95 \%$ & $2.32 \%$ \\
$E[T V]$ rel. to no tax & $100.00 \%$ & $99.60 \%$ & $101.43 \%$ & $102.69 \%$ & $129.90 \%$ \\
\hline * A boom starts in the first period in which the quarterly PD ratio exceeds a value of 250 and ends once it falls below 200. \\
+ Normal times are all those periods not classified as boom periods. \\
\hline
\end{tabular}

Table 10: Conditional Asset Price Moments

\begin{tabular}{|l|l|l|l|l|}
\hline Experience Groups & $6-11$ & $12-17$ & $18-23$ & $>23$ \\
\hline $0-5$ & 0.33 & 0.11 & 0.01 & 0.00 \\
\hline $6-11$ & - & 0.30 & 0.00 & 0.00 \\
\hline $12-17$ & - & - & 0.11 & 0.00 \\
\hline $18-23$ & - & - & - & 0.00 \\
\hline
\end{tabular}

Table A.1: P-values for Equality of Gain Estimates 


\begin{tabular}{|l|c|c|c|c|c|}
\hline & No Tax & $1 \%$ Tax & $2 \%$ Tax & $4 \%$ Tax & $10 \%$ Tax \\
\hline$E[P D]$ & 135.77 & 137.11 & 140.18 & 143.99 & 152.01 \\
$\operatorname{std}(P D)$ & 122.13 & 122.89 & 125.54 & 128.29 & 131.48 \\
$\operatorname{corr}\left(P D_{t}, P D_{t-1}\right)$ & 0.98 & 0.98 & 0.98 & 0.98 & 0.98 \\
$\operatorname{std}\left(r^{s}\right)$ & $11.63 \%$ & $11.72 \%$ & $11.97 \%$ & $12.26 \%$ & $13.78 \%$ \\
$E\left[r^{s}\right]$ & $2.11 \%$ & $2.12 \%$ & $2.15 \%$ & $2.19 \%$ & $2.41 \%$ \\
$\operatorname{corr}\left(P D_{t}, \bar{E}_{t} R_{t+1}\right)$ & 0.84 & 0.85 & 0.86 & 0.87 & 0.89 \\
$\operatorname{corr}\left(T V_{t}, T V_{t-1}\right)$ & 0.97 & 0.97 & 0.97 & 0.97 & 0.94 \\
$\operatorname{corr}\left(T V_{t}, P D_{t}\right)$ & 0.37 & 0.35 & 0.33 & 0.29 & 0.16 \\
$\operatorname{corr}\left(T V_{t},\left|P_{t} / P_{t-1}-1\right|\right)$ & 0.25 & 0.25 & 0.24 & 0.22 & 0.04 \\
$\operatorname{corr}\left(T V_{t}, \operatorname{std}\left(\widetilde{E}_{t}^{i} R_{t+1}\right)\right)$ & 0.95 & 0.94 & 0.93 & 0.91 & 0.87 \\
\hline$\#$ of booms per 100 yrs & 1.82 & 1.92 & 2.08 & 2.32 & 2.88 \\
average boom length $(q u a r t e r s)$ & 32.42 & 31.97 & 31.44 & 30.72 & 28.24 \\
average boom peak $(\mathrm{PD})$ & 491.01 & 487.57 & 484.54 & 478.82 & 468.96 \\
$E[T V]$ relative to no tax & $100.00 \%$ & $97.33 \%$ & $97.96 \%$ & $96.69 \%$ & $105.66 \%$ \\
\hline
\end{tabular}

Table A.2: Effects of introducing financial transaction taxes (no tax rebate) 


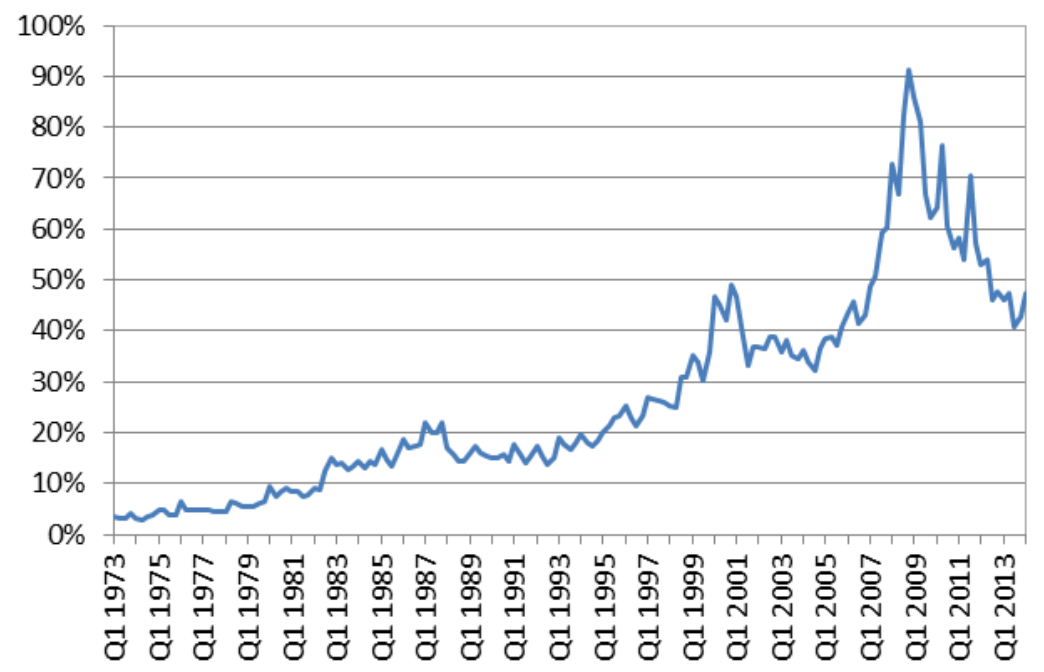

Figure 1: Quarterly trading volume (\% of outstanding shares, undetrended) 


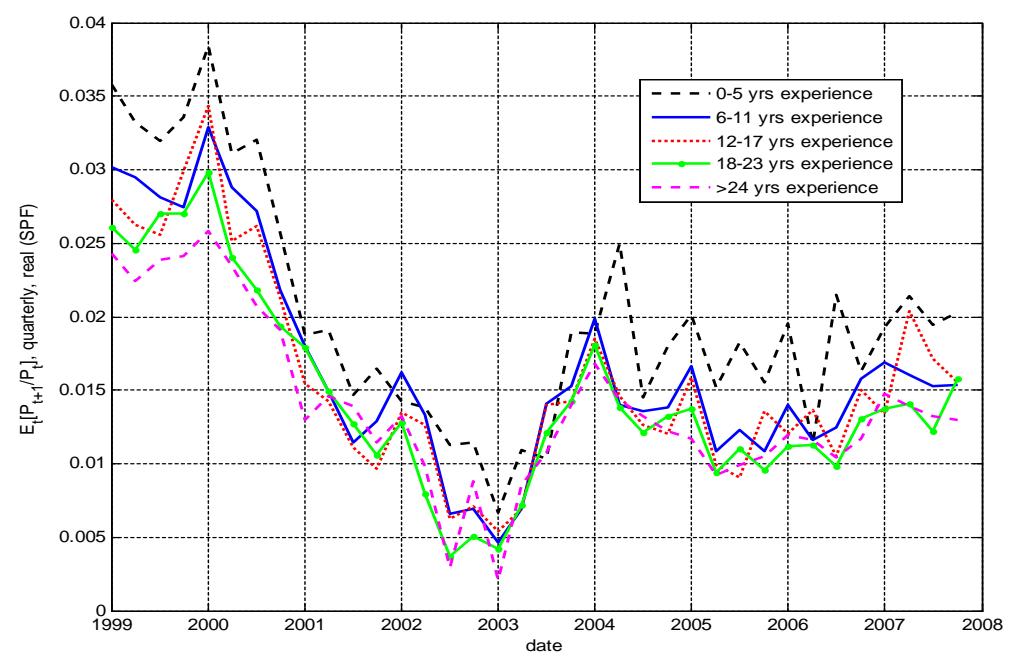

Figure 2: Price growth expectations by experience group (UBS survey, real, in quarterly growth rates)

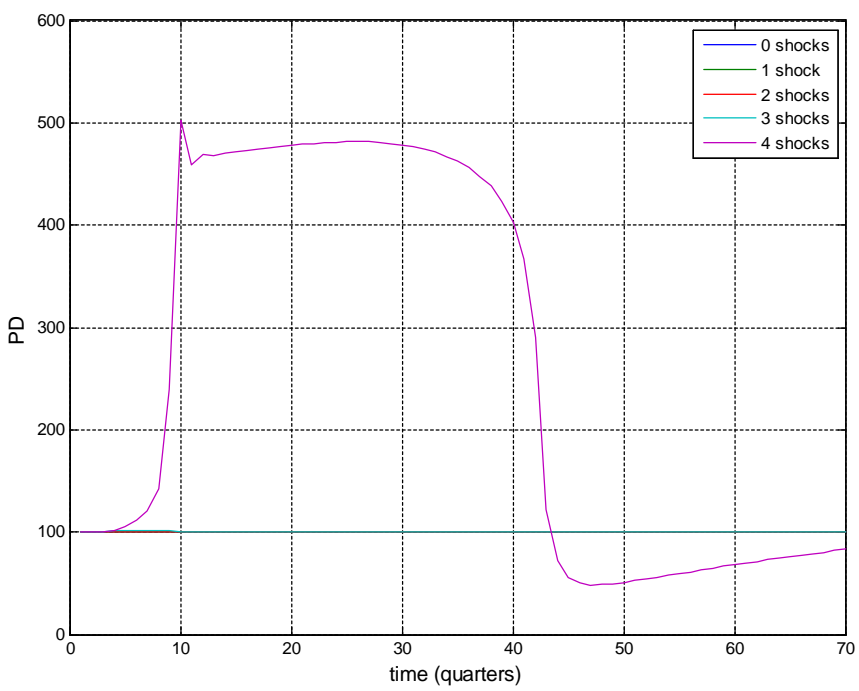

Figure 3: Response of the PD ratio to dividend growth shocks 

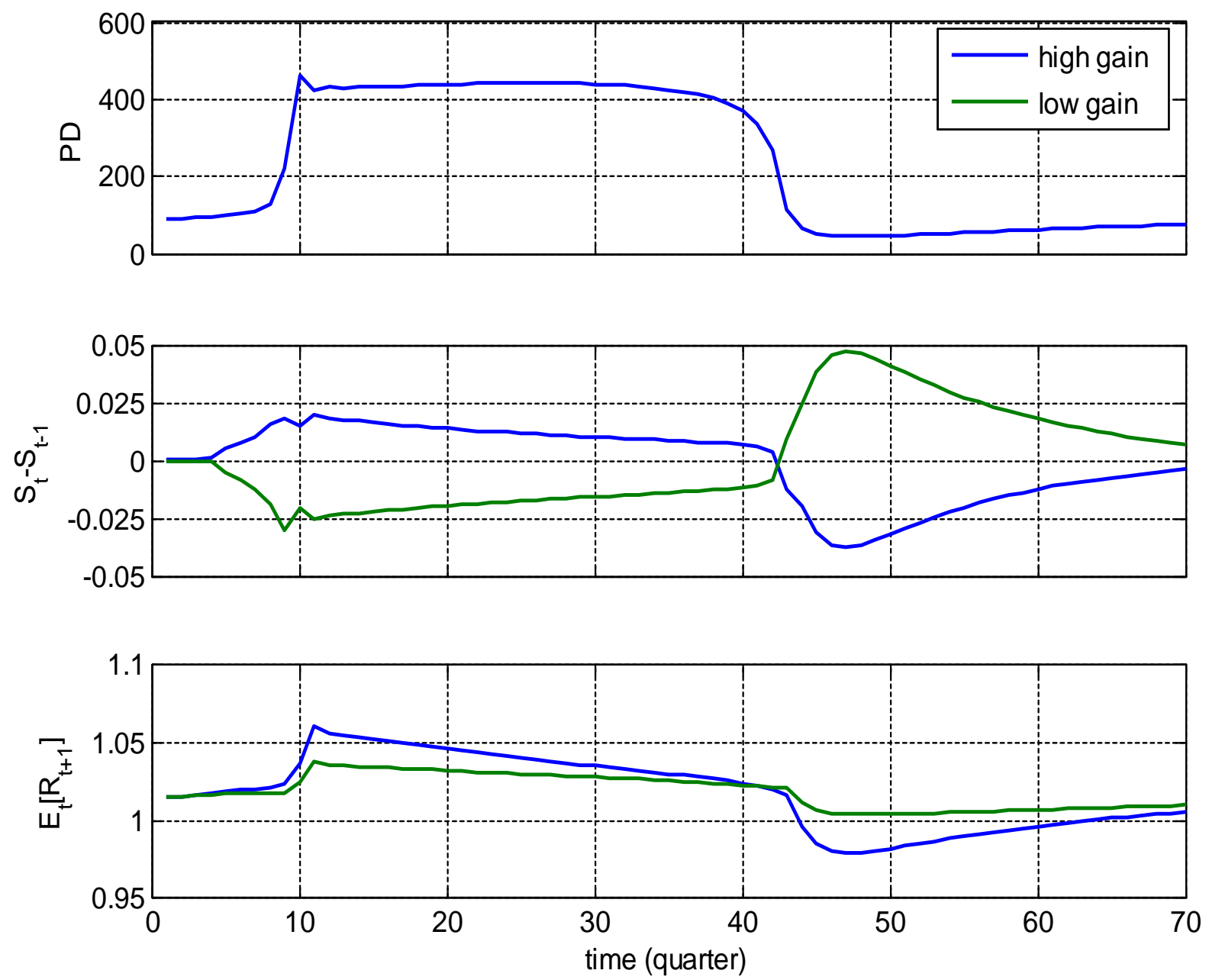

Figure 4: PD ratio, trading and return expectations over a boom-bust cylce (baseline model, no tax) 


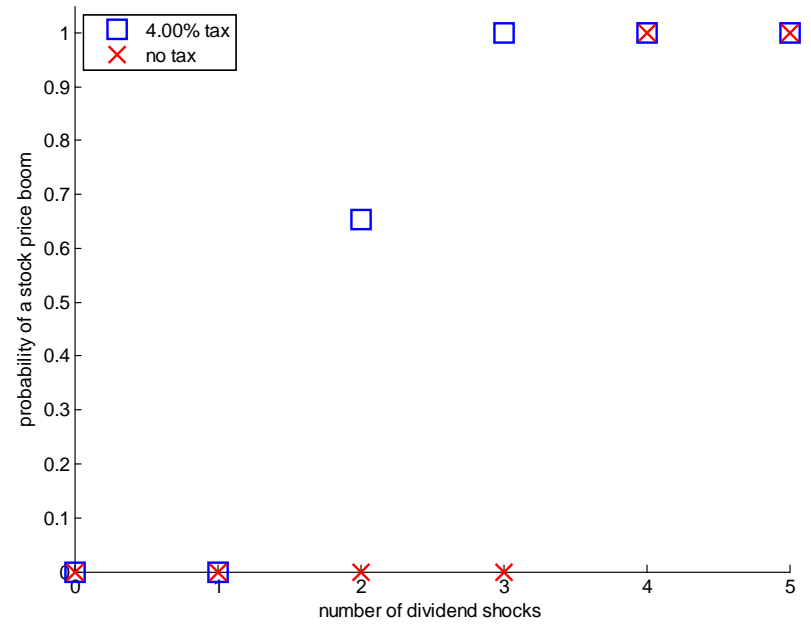

Figure 5: FTTs and the likelihood of stock price booms

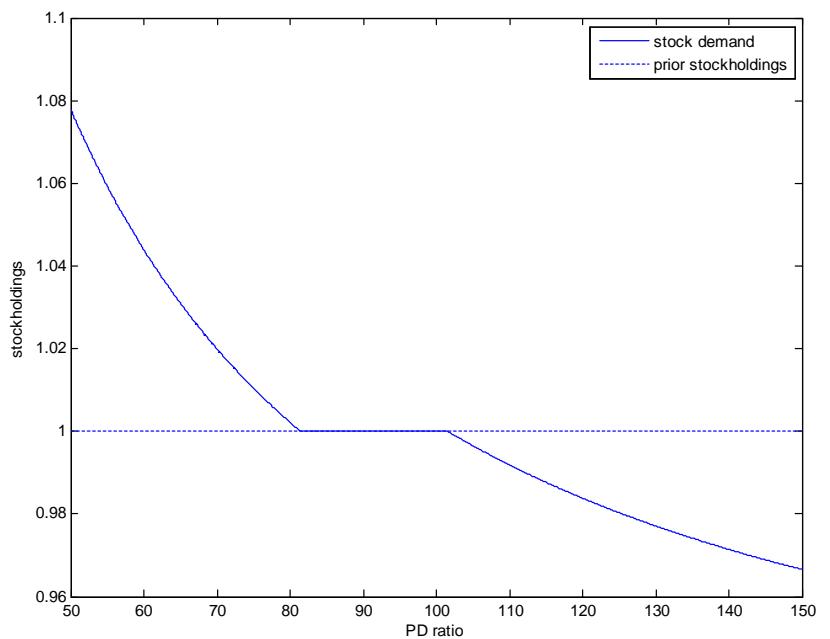

Figure 6: Stock demand function (4\% tax) 


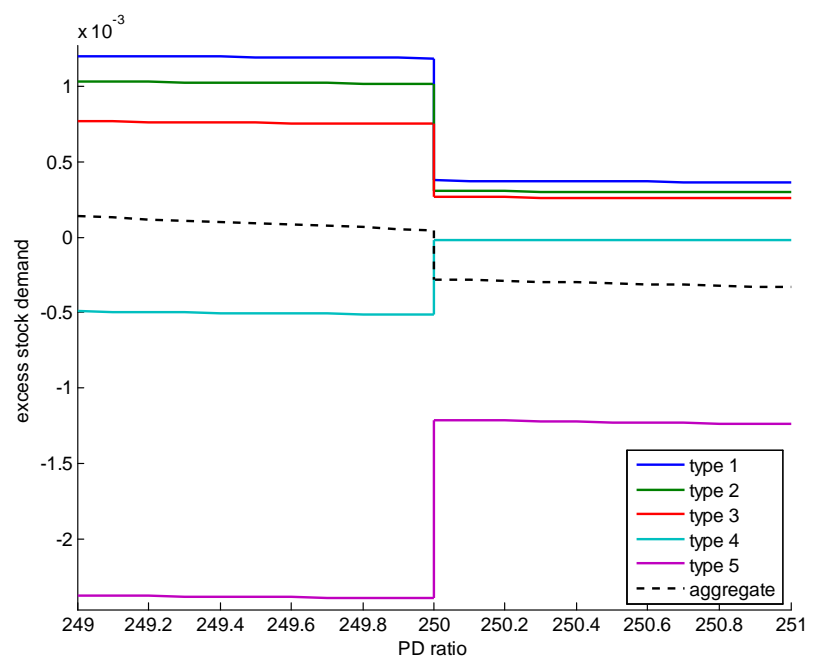

Figure 7: Non-existence of equilibrium with state-contingent FTTs

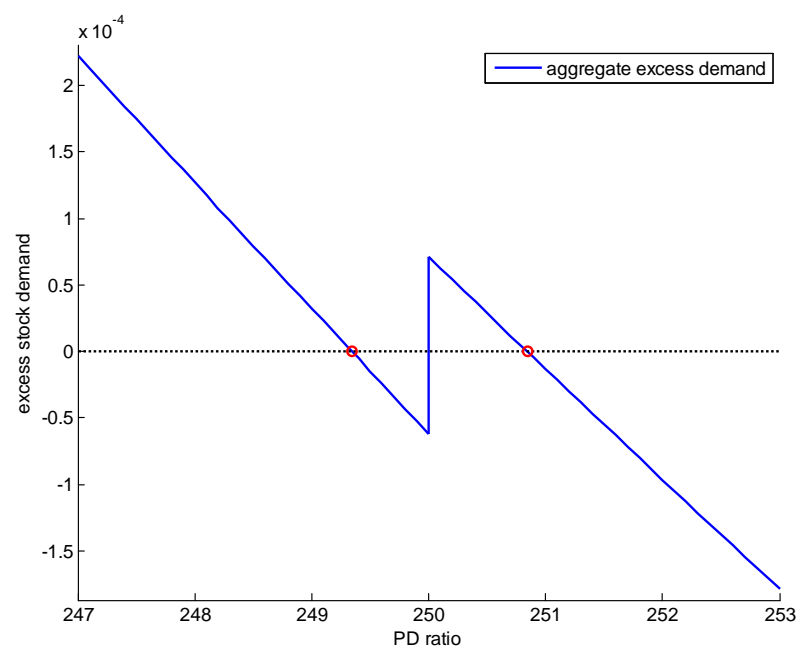

Figure 8: Multiple equilibrium prices with state-contingent transaction taxes 